\title{
THE ECOLOGICAL EFFECTS OF CATTLE GRAZING ON REPTILES AND SMALL MAMMALS IN A SAN JOAQUIN VALLEY GRASSLAND
}

\author{
A Thesis \\ presented to \\ the Faculty of California Polytechnic State University, \\ San Luis Obispo
}

\author{
In Partial Fulfillment \\ of the Requirements for the Degree \\ Master of Science in Biological Sciences \\ by \\ Michael William Tom
}

February 2014 
(C) 2014

Michael W. Tom

ALL RIGHTS RESERVED 


\section{COMMITTEE MEMBERSHIP}

TITLE:

The Ecological Effects of Cattle Grazing on Reptiles and Small Mammals in a San Joaquin Valley Grassland

AUTHOR:

Michael William Tom

DATE SUBMITTED:

February 2014

COMMITTEE CHAIR: John D. Perrine, PhD

Associate Professor of Biological Sciences

COMMITTEE MEMBER: $\quad$ Emily N. Taylor, PhD

Associate Professor of Biological Sciences

COMMITTEE MEMBER: Francis X. Villablanca, PhD

Professor of Biological Sciences 


\begin{abstract}
The Ecological Effects of Cattle Grazing on Reptiles and Small Mammals in a San

Joaquin Valley Grassland

Michael William Tom
\end{abstract}

Livestock grazing is a common and extensive land use practice in the United States occurring in a wide range of habitat types. As such, livestock grazing has the potential to alter ecosystem structure, function and community composition. The primary component (Chapter 1) of this thesis examined the effects of cattle grazing in a San Joaquin Valley grassland on two target taxa: reptiles and small mammals. The study took place on the Chimineas Unit of the Carrizo Ecological Reserve, San Luis Obispo County, California during Fall 2009 and Spring 2010. These taxa were sampled on matched pairs of two grazed and two ungrazed sites. Live trapping methods appropriate to sampling reptiles (coverboards and pit fall traps) and small mammals (Sherman live traps) were used to determine species richness and abundance of these taxa. Uta stansburiana (sideblotched lizard) abundances were greatest on Ungrazed1 (Fall: 1.75 \pm 0.49 captures/night, Spring: $3.58 \pm 0.35$ captures/night). In addition, Chaetodipus californicus (Spiny pocket mouse) abundance was also greatest on Ungrazed1. Population estimates generated by Program CAPTURE suggest $C$. californicus could be 6.27 times more abundant on Ungrazed1 than Grazed1. However, sample size issues and site level effects confounded and made it difficult to determine significant differences between the grazed and ungrazed treatments for both reptile and small mammal taxa. Habitat structure at these sites was also evaluated including small mammal burrow abundance and vegetation structure. Again, differences between the grazed and ungrazed pasture could not be discerned because of site level effects occurring among matched pairs. As such, this thesis illustrates the difficulty in studying grazing and its potential effects on biotic systems because an array of variables can make unclear the differences between grazed and ungrazed areas. As a follow up study (Chapter 2) I used logistic regression to model $U$. stansburiana presence to examine possible sources of variation observed at trapping array locations utilized in the main study (Chapter 1). Shrubs exhibited a quasi-complete separation of data points and the three best models included: 1) Bare soil cover (AICc = 28.12), 2) Holes (AICc = 29.76), and 3) Bare soil cover + Holes (AICc = 29.90). Shrubs, bare soil cover and small mammal burrow density were all positively associated with $U$. stansburiana presence at array locations. Although species have general habitat requirements based upon their ecology and evolution, variations in habitat utilization exists depending upon the resources present at a specific location. Quantifying basic ecological information on a site specific basis is important to managing populations by identifying important resources and habitat components utilized by a given species on a given site. 


\section{ACKNOWLEDGMENTS}

I would like to thank Dr. Perrine, Dr. Taylor, and Dr. Villablanca, for all of their guidance and assistance with the planning, execution of this thesis including field work, analysis as well as the preparation and finalization of this document and associated defense. Furthermore I would also like to thank California Department of Fish and Wildlife biologist Bob Stafford from the California Department of Fish and Wildlife for all his guidance in the planning of this thesis and for allowing this study to be conducted on the Chimineas property. I would also like to thank California Department of Fish and Wildlife biologist Craig Fiehler for assisting with the small mammal trapping portion of this thesis. Last but not least, I would like to thank all of those that assisted with hours of data collection for this thesis. 


\section{TABLE OF CONTENTS}

Page

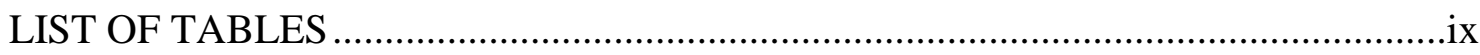

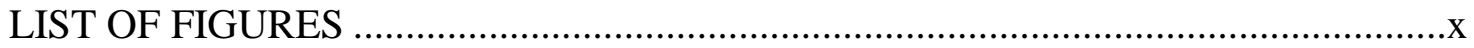

CHAPTER I. THE POTENTIAL EFFECTS OF GRAZING ON A SAN JOAQUIN VALLEY ANNUAL GRASSLAND

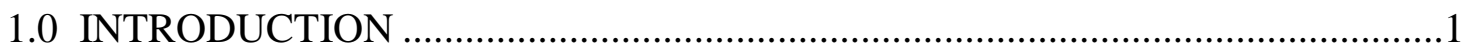

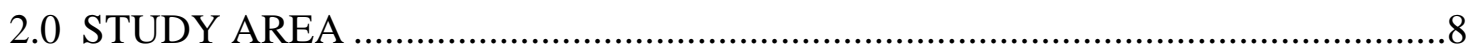

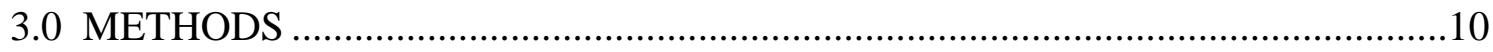

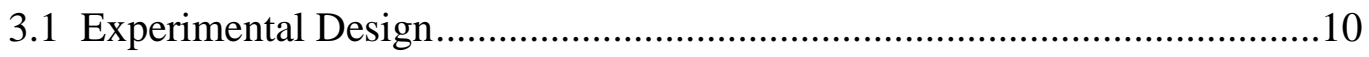

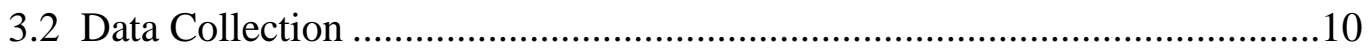

3.2.1 Reptiles ........................................................................ 10

A. Live Trapping .......................................................... 10

Methods................................................................ 10

Trap Checking........................................................ 12

Data Collection .......................................................12

Analysis............................................................. 13

B. Visual Encounter Surveys ..............................................14

Methods..................................................................14

Analysis............................................................. 14

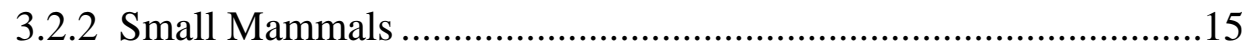

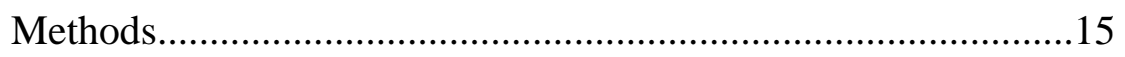

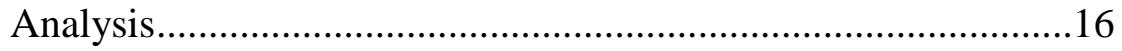

3.2.3 Habitat Structure .............................................................. 17 


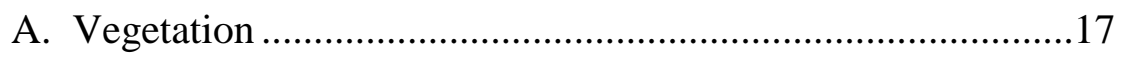

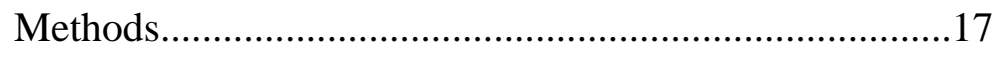

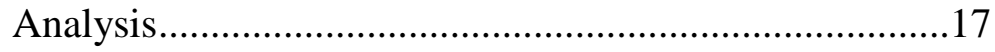

B. Small Mammal Burrows ..........................................................19

Methods ......................................................................19

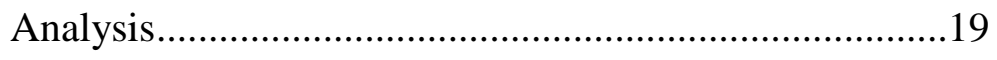

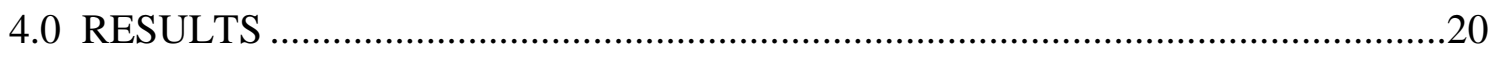

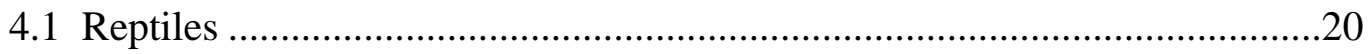

A. Live Trapping ......................................................................20

Fall (October and November 2009) …………………....20

Main Study (April and May 2010)..................................20

B. Visual Encounter Surveys ....................................................21

Fall (October and November 2009) ................................21

Main Study (April and May 2010)...................................22

4.2 Methods Comparison .............................................................................22

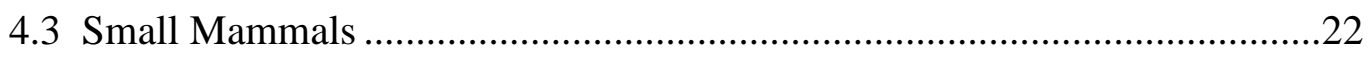

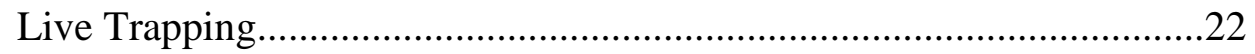

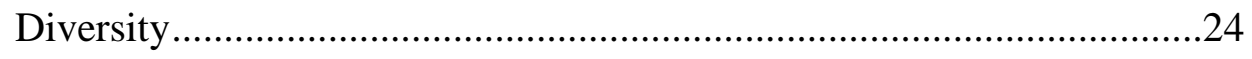

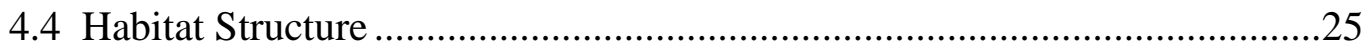

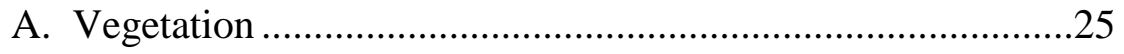

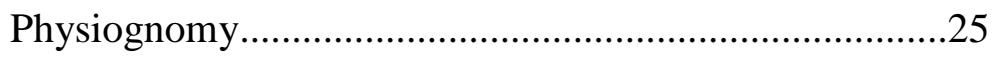

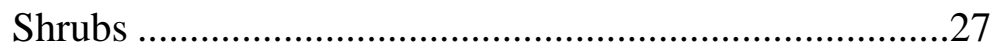


B. Small Mammal Burrows ...........................................................28

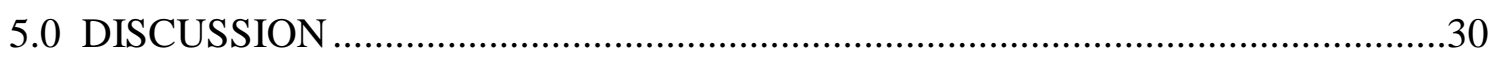

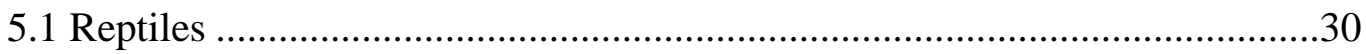

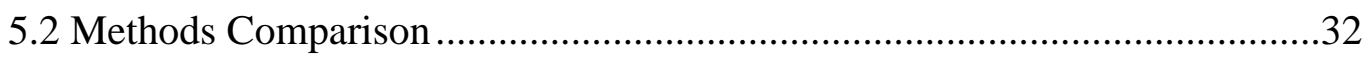

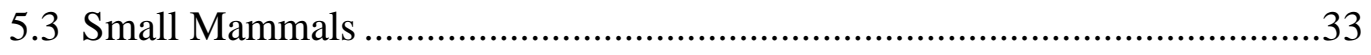

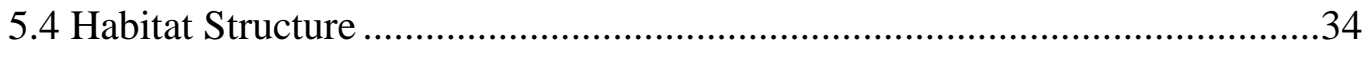

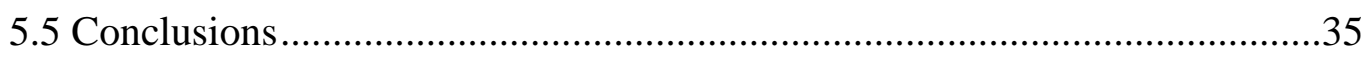

CHAPTER II. HABITAT PREFERENCE AND UTILIZATION OF THE COMMON SIDE-BLOTCHED LIZARD (UTA STANSBURIANA) IN A SAN JOAQUIN VALLEY GRASSLAND

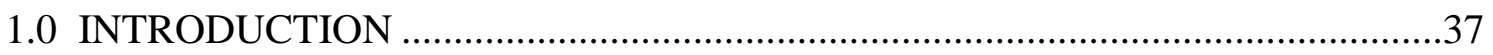

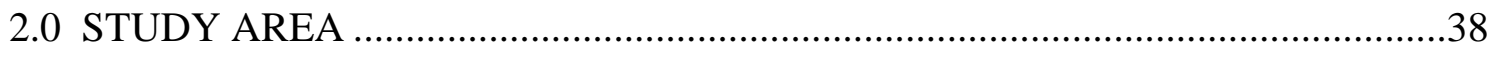

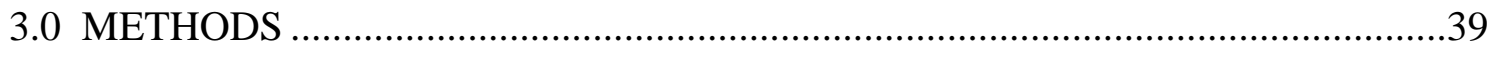

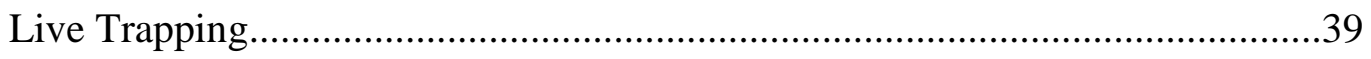

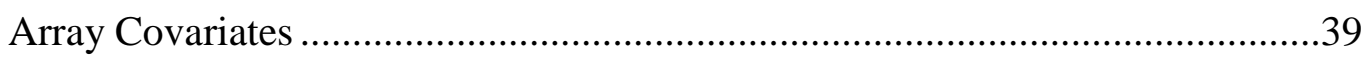

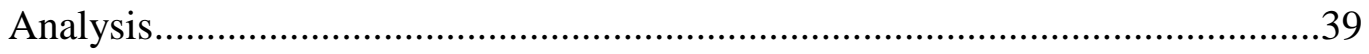

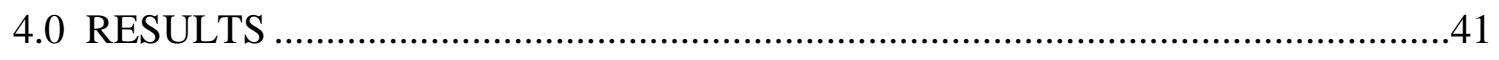

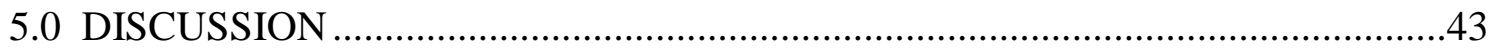

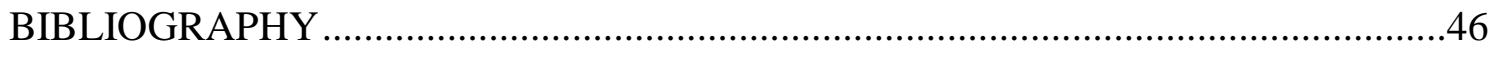

\section{APPENDICES}

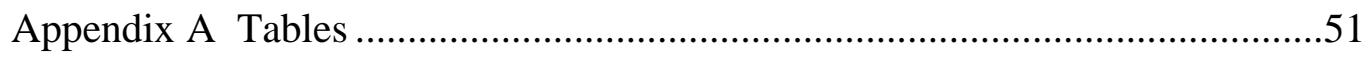

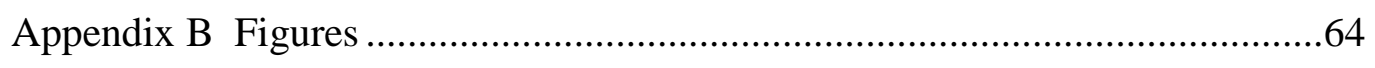




\section{LIST OF TABLES}

Table

Page

1. UTM coordinates (Zone 11S) for live trapping arrays used to sample reptiles .........51

2. Dates in which reptile trapping occurred during fall 2009 and spring 2010

3. Summary of total captures among live trapping arrays and visual encounter surveys for reptile species captured during fall 2009 and spring 2010

4. Summary of total reptile captures for each individual array across coverboards and drift fences with live traps. This summary reflects reptiles captured during the spring 2010 field season. Grazed2 and Ungrazed2 were not sampled during spring 2010

5. An analysis of some attributes associated with sampling for reptiles using drift fences with live traps, cover boards, and visual encounter surveys.

6. Summary of small mammal captures, observed richness and estimated richness during Fall 2009. Trapping effort consisted of 500 trap-nights per site

7. Summary of observed unique captures and population estimates calculated derived from mark-release-recapture data and capture probabilities (CAPTURE) for five small mammal species on a grazed and ungrazed site during fall 2009 .......57

8. Average \pm SE basal and canopy coverage estimated from point intercept data .58

9. Chi-square table for small mammal burrow entrance diameters

10. Summary of habitat covariates used to explain Uta stansburiana presence at array locations....

11. Results of univariate logistic regression analysis for individual covariates hypothesized to predict Uta stansburiana presence at an array

12. Correlation matrix of covariates hypothesized to predict Uta stansburiana presence at arrays whose univariate analysis likelihood ratio p-value was <0.25. Pearson correlation coefficient / $\mathrm{p}$-values in bold indicate pairs of covariates that were $>60 \%$ correlated

13. Results of logistic regression analysis for all combinations of remaining covariates hypothesized to predict Uta stansburiana presence at arrays once non-significant and variables that were $>60 \%$ correlated were removed 


\section{LIST OF FIGURES}

Figure

Page

1. Map depicting San Luis Obispo County, California and the location of the Chimineas Unit of the California Department of Fish and Game Carrizo Ecological Reserve

2. Map of the study area with locations of each matched pair of sites

3. Photographs of each site representing the typical grassland habitat in this region. Photos were taken in May of 2010. a) Ungrazed1 facing east b) Grazed1 facing west c) Ungrazed2 facing east d) Grazed2 facing west.

4. (a) A fully functional live trapping array with drift fence and coverboards.

(b) Over view of a live trap at the end of a drift fence with two funnels leading into a five gallon bucket.

5. Average \pm SE Uta stansburiana captures/night during two sampling seasons on two grazed and two ungrazed sites. Sites Grazed 2 and Ungrazed 2 were not sampled during the fall

6. Average \pm SE Uta stansburiana encounters/person-hour during visual encounter surveys of the Fall 2009 pilot study. *Species not detected

7. Uta stansburiana encounters/person-hour for four visual encounter survey occasions during the Fall 2009 pilot study

8. Starting temperature versus $U t a$ encounter rate for 4 visual encounter survey occasions during fall 2009 on Ungrazed 1

9. Relative frequency of the minimum number known alive for each small mammal species captured over 500 trap-nights per site

10. Capture probability based population estimates generated from mark-releaserecapture data analyzed with program CAPTURE for four small mammal species on Grazed 1 and Ungrazed1. Error bars represent $95 \%$ confidence intervals. These confidence intervals are non-symmetrical as most of the error is in estimating the portion of the population that was not captured

11. Small mammal species richness analysis using program EstimateS. Individual based Coleman rarefaction curve of the accumulated number of species as a function of the number of individuals captured

12. Average \pm SE canopy cover during spring 2010 estimated from point intercept data for forbs, grasses and shrubs. Shrubs were encountered only at Ungrazed 1 ....75 
Figure

13. Average \pm SE basal cover during spring 2010 estimated from point intercept data for bare ground, forbs, grasses and litter

14. Average \pm SE canopy height during spring 2010 estimated from point intercept data on two grazed and two ungrazed sites. Average values for each site were calculated using the average canopy height of the sampling points within each transect

15. Average \pm SE number of shrubs/transect for Grazed1 and Ungrazed1 during spring 2010. Shrubs were not encountered on Grazed2 and Ungrazed2.......78

16. Distribution of shrub heights at Grazed1 and Ungrzed1 found on strip Transects

17. Average \pm SE number of holes/transect for two grazed and two ungrazed sites during spring 2010 .

18. Distribution of small mammal hole entrance diameter for two grazed and two ungrazed sites. Entrance diameters were classified as either less than $2 \mathrm{~cm}$, $2 \mathrm{~cm}-4 \mathrm{~cm}, 4 \mathrm{~cm}-8 \mathrm{~cm}$ or greater than $8 \mathrm{~cm}$

19. Average $\pm \mathrm{SE}$ number of burrows at arrays where Uta stansburiana was observed and at arrays where Uta stansburiana was not detected

20. Average \pm SE canopy height of grasses and forbs at arrays where Uta stansburiana was observed and at arrays where Uta stansburiana was not detected. Average height at an array was calculated using the average height at each quadrat

21. Average \pm SE percent cover of grasses, forbs, and bare ground at arrays where Uta stansburiana was observed and at arrays where Uta stansburiana was not detected. Average percent cover was calculated using the average cover across quadrats at an array 


\section{CHAPTER I}

The Potential Effects of Grazing on a San Joaquin Valley Annual Grassland

\subsection{INTRODUCTION}

Grazing by livestock such as cattle, horses, and sheep represents an extensive agricultural land use practice in the western United States. Approximately $70 \%$ of the land area encompassing federal, public as well as private lands is used for grazing by livestock (Council for Agricultural Science and Technology, 1974). Grazing is permitted on the majority of Bureau of Land Management lands as well as portions of National Park and U.S. Forest Service lands, wilderness areas and Wildlife Refuges (U.S. General Accounting Office, 1988). Habitats such as grasslands, forests, deserts, woodlands and sage scrubs can be sensitive to grazing by livestock (Fleischner, 1994). Ultimately livestock grazing has the capacity to alter ecosystem structure, function and community composition within these habitats (Franklin et al., 1981).

Livestock grazing can impose potentially deleterious bottom-up effects on ecosystems. For example, grazing activities can promote desertification by compacting soil and inhibiting water penetration (Alderfer and Robinson, 1949). Soils that are disturbed by livestock can show marked reductions in nitrogen (up to 80-100\%) that is available to plants by inhibiting nitrogen-fixing microbes occurring in soil crusts (Belnap et al., 1994). The reduction in available nitrogen is of special concern in ecosystems, such as deserts, where nitrogen is a limiting factor (Fleischner, 1994).

Livestock grazing can also alter the physiognomy of plant communities. For example, in a Washington ponderosa pine (Pinus ponderosa) forest, cattle transformed the forest from a relatively open mosaic of pine trees and grasses to a densely canopied 
forest lacking a grass dominated understory (Rummel, 1951). Contrastingly, livestock grazing reduces shrub and herbaceous plant production, in turn lessening the amount of available cover on the landscape (Jones, 1981). Actively grazed areas, for the most part, remain as early seral communities. In a study by Glinski (1977), livestock grazing inhibited the recruitment of cottonwood (Populus fremontii), an important component of later seral stages, by trampling and ingestion of individuals (Glinski, 1977).

Consequently, livestock have the potential to decrease plant diversity based of different plant species' variable vulnerability to consumption (Fleischner, 1994).

Riparian habitats are highly vulnerable to livestock grazing. Grazing greatly reduces streamside vegetation, decreases overall cover and increases soil compaction (Kaufman and Krueger, 1984). The results of these impacts can manifest as higher streamside and instream temperatures and increased runoff (Van Velson, 1979). Siltation and sediment build up created by the removal of streamside vegetation can modify stream morphology as well (Platts, 1981).

The effects of livestock grazing are not just limited to plant communities. Studies of a variety of animal taxa tended to observe reduced species richness and relative abundance at grazed areas relative to ungrazed areas. For example, a small mammal study in Idaho observed a reduction in diversity and density on grazed sites (Reynolds and Trost, 1980). In Utah, a study investigated the response of passerines, raptors and small mammals to the removal of livestock grazing for an eight year period. Eight years after the removal of livestock, diversity rose by $350 \%$ (Duff, 1979). Livestock grazing can also influence the population sizes of numerous species. According to Keller and Burnham (1982), trout populations and body mass both increased when livestock were 
removed from surrounding riparian areas. Comparatively, a population of wandering garter snake (Thamnophis elegans vagrans) was five times more abundant at ungrazed sites than grazed sites (Szaro et al., 1985).

Most studies of the impacts of grazing on vertebrate species have focused on only a single species or a few target species. Information on the effects of livestock grazing on biological communities is lacking, especially for the class Reptilia. The majority of work to date within the class Reptilia has focused on lizard communities. In the California Mojave desert, lizard communities were evaluated on a heavily grazed site and a control site (Busack and Bury, 1974). Lizard abundance for the majority of species was twice as large and biomass was 3.7 times as great at the ungrazed site than the grazed site. Zebra tailed lizards (Callisaurus draconoides), however, were much more abundant on the grazed site. Busack and Bury (1974) attributed these differences in abundance and biomass to loss of cover, reduction in food availability, disturbance of social structure and direct casualties due to trampling.

Jones (1981) examined lizard abundance and diversity in western Arizona at heavily-grazed versus lightly-grazed plots. Lightly-grazed plots had greater lizard diversity and abundance than heavily grazed plots across different habitat types. Jones (1981) also examined the lizard assemblages at each site based on foraging strategy. Widely foraging and open space adapted species were generally more abundant at lightlygrazed sites than heavily-grazed ones. Interestingly, sit and wait predators were more abundant on heavily-grazed sites. Jones (1981) concluded that livestock influence the structure of lizard communities by altering habitats and decreasing invertebrate prey. Specifically, livestock grazing decreases diversity by simplifying habitat structure which 
reduces the number of available niches. Consequently, structural influences favored some foraging strategies while selecting against others. Grazing increased the amount of downed debris resulting in greater abundances of lizards that rely on that resource to successfully forage (Jones, 1981). Conversely, grazing negatively affected widely foraging species by drastically decreasing low lying vegetative cover.

Bock et al. (1990) examined the abundance of the bunchgrass lizard (Sceloporus scalaris slavini) across heavily grazed and ungrazed (22 years) treatments in Santa Cruz County, Arizona. Relative abundance of greater bunchgrass lizards was higher in the ungrazed treatment than the grazed treatment. Moreover, the lizards found in the grazed treatment were exclusively associated with intact bunch grasses. Bock et al. (1990) attributed the differences in bunchgrass lizard abundance to 1) the lack of bunch grasses in heavily grazed areas and 2) increased predation (bunchgrass lizards are relatively slow and require vegetative cover to escape from predators).

Beever and Brussard (2004) studied the effects of feral horse grazing on both reptile and small mammal diversity and abundance in the Great Basin. Reptiles were sampled within plots using visual based surveys. Reptile diversity was greater on average in areas without horse grazing than areas with horse grazing (Beever and Brussard, 2004). Also, seven of nine reptile species were more abundant in areas unoccupied by horses. Despite these differences however, Beever and Brussard (2004) were reluctant to associate the differences with the presence of the horses. Instead they believed that an array of random factors could have produced the associations that they observed. 
Even though these studies consistently observed reductions in vertebrate abundance and species diversity at grazed areas, they are subject to criticism. A review by Brown and McDonald (1995) addresses the problems apparent in past studies. They noted that the majority of studies suffered from pseudoreplication or lack of replication and thus could not generalize their results. They also observed that other studies that examined the effects of grazing by native small mammals and other native herbivores showed comparable results to livestock grazing studies. Brown and McDonald (1995) concluded that both grazing by livestock and grazing by native herbivores can reduce biomass, change vegetative structure and species composition, and alter ecosystem processes.

Despite the numerous studies which attempt to illustrate the deleterious effects of livestock grazing, this land use practice may be a useful management tool. A review by Germano et al. (2001) examines the possibility of using livestock in the San Joaquin Valley, California as a management tool to thin exotic grasses in an effort to conserve declining endemic species. Originally the San Joaquin Valley was typified by open habitats such as salt bush scrub. Currently, these open habitats are being replaced with dense monotypic patches of exotic grasses. Germano et al. (2001) proposed that livestock grazing could be used to manage exotic grasses, thus benefiting open habitat associated species that are otherwise in decline.

They argue that many San Joaquin Valley native species would benefit from grazing because of their adaptions to relatively open habitats. Radio-tracking studies show that blunt nosed leopard lizards (Gambelia sila) preferred relatively open areas 
including grazed pastures. Also coast horned lizard (Phrynosoma coronatum) decline correlated with an increase in exotic grass cover.

Snakes are underrepresented in grazing studies. Only two studies (Beever and Brussard, 2004; Szaro et al., 1985) attempted to include snakes in their analyses and only Beever and Brussard (2004) attempted a snake community analysis. Snakes are traditionally viewed as poor study organisms for ecological, behavioral, and physiological research (Huey et al., 1983). Difficulties in using snakes as a study organism include restrictions in sample size and the use of accurate sampling methods. Snakes occur at relatively low density thus adequate sample sizes are often difficult to obtain. Also snakes are difficult to observe since they are secretive and can exhibit long periods of inactivity (Seigel, 1993). Because of these factors the majority of reptile research is done on lizards. Seigel (1993) explains that using snakes as a "model" organism requires the use of new and innovative methods. Many studies of snakes, including those studies previously discussed, are based on hand capture and search methods which produce unreliable estimates of abundance and diversity. For instance, snakes active at night would not be observed during daytime searches. Very few studies on snakes utilized intensive or exhaustive methods. In addition, the majority of studies that involve sampling snake populations tend to utilize a single method and are in fact biased towards capturing only a subset of the snake community (Kjoss and Litvaitis, 2001). Thus studies focused on snake communities require the deployment of multiple methods to obtain reliable data.

Given the possible but poorly resolved effects of grazing, the aim of this study was to examine the potential effects of cattle grazing on reptile and small mammal 
communities in a San Joaquin Valley annual grassland. The objectives of this study were to quantify and compare between grazed and ungrazed treatments (1) reptile community composition (diversity and abundance), (2) small mammal community composition (diversity and abundance) and (3) habitat structure (plant community physiognomy and small mammal burrow abundance).

Based upon these objectives, three $a$ priori hypotheses and predictions were developed:

Hypothesis 1: Grazing negatively affects the diversity and abundance of reptiles. Prediction 1: Reptile diversity and abundance will be lower at grazed sites than ungrazed sites.

Hypothesis 2: Grazing negatively affects the diversity and abundance of small mammals.

Prediction 2: Small mammal diversity and abundance will be lower at grazed sites than ungrazed sites

Hypothesis 3: Grazing alters habitat structure.

Prediction 3: Vegetative cover, height, shrub abundance, and small mammal burrow abundance will be lower at grazed sites than ungrazed sites. 


\section{$\underline{\text { 2.0 STUDY AREA }}$}

This study occurred within the Chimineas Unit of the Carrizo Ecological Reserve, a 31,000 acre California Department of Fish and Game property located west of the Carrizo Plains National monument in southeastern San Luis Obispo County, California (Figure 1). Chimineas is part of the San Joaquin Valley subregion of the Great Central Valley region of the California Floristic Province (Hickman, 1993). Average yearly rainfall in the vicinity within the past seven years was 8.67 inches. Total rainfall for the 2010 calendar year was 14.19 inches (data is from a weather station located on the Chimineas property).

The Carrizo Plains Ecological Reserve provides a protected corridor between the Carrizo Plains National Monument and the Los Padres National Forest. Two mountain ranges, the La Panza range and the Caliente range, lie west and southeast of the property respectively. Anthropogenic activities that occur on the Chimineas property include cattle grazing, hunting, and management of wildlife habitat.

The study area was located on the northern portion of the property. Elevation ranged from 730 to 830 meters. A north to south main dirt road (Figure 2) and a barbed wired fence separated two pastures. Both pastures were previously used for agriculture (crop production). Following crop production, the western pasture was used as grazing land for cattle while the other pasture was enrolled into the Conservation Reserve Program approximately 20-30 years ago. Grazing on the western pastured has occurred seasonally over approximately the past 20 years (personal communication Bob Stafford, 2009). In 2009 and 2010 stocking rates for the grazed pasture were 460 and 548 total cattle respectively and averaged 547 individuals within the past seven years. During this 
study cattle were present during October and November 2009, but not during April and May 2010. This portion of the property was chosen because it contained the best juxtaposition of grazed and ungrazed treatments to minimize local-scale variation between sites.

Topography of the study area consisted of gently rolling hills with no rocky outcrops. The ungrazed pasture was dominated by annual grassland habitat which consisted primarily of mixed naturalized and native annual grasses and forbs. Contrastingly, the plant species and landscape observed on the grazed pasture was dependent upon the presence of cattle. When cattle were present the landscape was dominated by bare soil cover and infrequent patches of short vegetation. However, when cattle were not present, the vegetation was much more extensive and bare soil cover lessened. Four grass species commonly occurred as a mosaic within the study area: ripgut brome (Bromus diandrus), soft chess brome (B. hordeaceus), common wild oat (Avena fatua), and red brome (B. madritensis). Some purple needle grass (Nessella pulchra) was also uncommon at the study area. The majority of low forb cover consisted of a species of filaree (Erodium sp.) and fiddleneck (Amsinckia sp.), both annual herbs. Other forb species that represented a minimal proportion of the vegetation at the site included short-pod mustard (Hirschfeldia incana), California poppy (Eschscholzia californica) and miniature lupine (Lupinus bicolor). Shrub species observed within the study area included interior goldenbush (Ericameria linearfolia), coastal buckwheat (Eriogonum fasciculatum), and California juniper (Juniperus californicus) (Figure 3). These shrub species were more prevalent on the ungrazed pasture. 


\subsection{METHODS}

\subsection{Experimental Design}

I sampled the reptile community, small mammal community as well as habitat structure on two matched pairs of sites (Grazed1/Ungrazed1 and Grazed2/Ungrazed2) (Figure 2). Each matched pair consisted of one grazed and one ungrazed site each located $50 \mathrm{~m}$ from the main road to minimize confounding road effects. The first matched pair was located a randomly determined distance of $658 \mathrm{~m}$ south along the main road from the entrance to the ranch property. The second matched pair was located 1 mile farther south on the main road. This matching scheme was intended to minimize random factors because sites that are close together have a higher probability of having similar conditions and influence by chance events (Hurlbert, 1984). Grazed1 and Ungrazed1 occurred at an elevation $25 \mathrm{~m}$ lower than Grazed2 and Ungrazed2. Site dimensions were $250 \mathrm{~m} \times 250 \mathrm{~m}$.

\subsection{Data Collection}

\subsubsection{Reptiles}

Combinations of methods for sampling herpetofauna were used because any one method alone may only sample a subset of the community (Kjoss and Litvaitis, 2001). Standard methods for sampling herpetofauna used by this study included visual encounter surveys and live trapping methods.

\section{A. Live Trapping}

Methods. Trapping arrays were constructed at sites to sample for reptile species. The trap design deployed was a combination of two standard trap designs for sampling reptiles: pitfall traps and funnel traps. I designed my traps in this fashion to lessen 
mortality from high temperatures and predation and to prevent escape of large snakes. Each trapping array consisted of a $5 \mathrm{~m}$ long drift fence made of aluminum flashing that was $30 \mathrm{~cm}$ tall and set $5 \mathrm{~cm}$ beneath the soil surface to prevent animals from crossing underneath (Figure 4a). Rebar driven into the ground helped stabilize the aluminum flashing. Each drift fence was fitted with two partially buried five gallon plastic paint buckets, one at each end of the drift fence. I chose to bury the buckets because the surrounding soil would help to insulate captures from high temperatures. Bucket lids were included to also limit direct sun exposure, prevent escape of large snakes, and to shelter captures from predation. Different from traditional pitfall traps, the top $5-10 \mathrm{~cm}$ of each bucket was exposed above the soil surface to accommodate two funnels (one for each side of the drift fence) (Figure 4b). Each funnel was inserted into a $6.3 \mathrm{~cm}$ diameter hole drilled into the side of the bucket and set flush to the drift fence and the soil surface. The funnels functioned as an entrance into the bucket and once inside the chance of an escape would be unlikely because the end of the funnels protruded $3-5 \mathrm{~cm}$ into the buckets. The funnels were constructed from quarter inch hardware cloth and large plastic cups. The diameters of the narrow and wide end of the funnel were $6.3 \mathrm{~cm}$ and $13 \mathrm{~cm}$ respectively. Traps were designed so that funnel entrances could be plugged when not in use. In each bucket I placed a plastic cup and damp sponge to prevent possible predation from other captured animals and to prevent desiccation of captured amphibians.

Each drift fence was also supplemented with two $2 \mathrm{x} 4 \mathrm{ft}$ white painted plywood cover boards each placed $1 \mathrm{~m}$ from the ends. The use of artificial cover such as plywood boards is a standard and proven method for sampling herpetofauna (Fellers and Drost 1994). Compared to other materials such as sheet metal, wood boards provide animals 
with greater insulation from high temperatures and can also be adequate refugia (Fitch 1987).

Each site contained five trapping arrays arranged in a cross pattern (20 arrays total). The geographic coordinates for each array is located in Table 1. This arrangement consisted of one central array and four outer arrays each 90 degrees apart and $75 \mathrm{~m}$ from the center. I intended on using this arrangement to account for the variation from potential environmental gradients on sites.

I conducted two trapping seasons: a pilot study (October-November 2009) and a main study (April-May 2010) during months in which reptile activity is generally high (Stebbins, 2003). During the pilot study, trapping occurred on Grazed1 and Ungrazed1 over the course of 12 nights (five weekend sessions) for a total of 60 array-nights per site (Table 2). The main study included all four sites and occurred over the course of 17 nights (seven weekend sessions) for a total of 85 array-nights per site. I performed this work under Cal Poly IUCAC Protocol \#921 and a CDFG Volunteer Agreement. Trap Checking. During both studies, when traps were open, each array was checked once daily between $9 \mathrm{am}$ and $11 \mathrm{am}$. Cover boards were checked by quickly lifting the board and attempting to capture and identify reptiles, amphibians and small mammals found underneath. I attempted to capture all individuals found under cover boards. Incidental observations of reptiles were also recorded while en route to arrays but were not included in formal analyses.

Data Collection. The full suite of data described herein was collected for reptiles that I was able to secure in hand. All reptiles regardless of whether they were handled or not were identified to species. All reptiles that did not escape were first photographed and 
then placed into clear zip-loc bags. Once in zip-loc bags, I measured each individual's snout-vent length and mass (using a Pesola spring scale). I also determined sex if possible for side-blotched lizards and snakes. Male side-blotched lizards are identified by having two large post anal scales and enlarged femoral pores. Snake sex identification is more complicated and involved inserting a blunt probe into the vent towards the tail. In female snakes, the probe will meet resistance and in males the probe can be inserted farther into the tail region depending upon the length of the inverted hemipenis. Following sex determination I collected tissue samples from captures. Tissue samples were collected using a sharp pair of dissecting scissors and consisted of clipping a ventral tail scale for snakes and toe clipping for lizards. Before clipping the dissecting scissors were sterilized with $70 \%$ ethanol. Samples were immediately stored in ethanol and deposited at the Biological Sciences Department at California State Polytechnic University in San Luis Obispo.

Lastly, I marked captured snakes and lizards for individual identification. Snakes were marked with a passive integrated transponder (PIT) injected using an applicator syringe cleaned with $70 \%$ ethanol. After insertion, the application site was wiped with ethanol. Lizards were marked by clipping a unique combination of toes with dissecting scissors cleaned with $70 \%$ ethanol. After collecting data on captured individuals I released animals within five meters of the array of capture.

Analysis. Because trapping dates were not independent of one another, it was inappropriate to use either parametric or non-parametric analyses. Instead, the data collected was described using a qualitative analysis. The counts of coverboard captures and drift fence captures per day were combined for the qualitative analysis. 


\section{B. Visual Encounter Surveys}

Methods. Visual encounter surveys are a standard method for measuring richness, composition of a species assemblage and determining the relative abundance of reptiles and amphibians (Crump and Scott, 1994). On each site, one to two searchers followed a set sinusoidal path walking a total of $2000 \mathrm{~m}$ per survey. Searchers actively examined all microhabitats (i.e., overturned loose woody debris, rocks, shrubs, and burrow entrances) and scanned for herpetofauna along and within $5 \mathrm{~m}$ of the path. There was no destructive dismantling of refugia. If searchers overturned woody debris and rocks they returned these cover objects to their original position. The surveyors recorded the total number of individuals for each species encountered as well as the search duration and initial air temperature.

Visual encounter surveys were performed on four occasions during fall 2009 on sites Grazed 1 and Ungrazed 1 as a pilot study. Spring visual encounter surveys were also attempted on all four sites on two occasions. The time in which these surveys were conducted coincided with the live trapping study seasons.

Visual encounter surveys were performed once a week at each site. To eliminate the chance of surveyors disturbing animals, visual encounter surveys were done prior checking trapping arrays. The order in which sites were searched was randomized for each visual encounter survey occasion.

Analysis. To describe the patterns in data for visual encounter surveys, a qualitative analysis of the differences in diversity and abundance was made between sites. To account for differential effort across surveys, I used counts per unit effort (the number of observations per person-hour) as an index of abundance for each species. 


\subsubsection{Small Mammals}

Methods. I deployed two north to south parallel transects on both Grazed1 and Ungrazed1. Site accessibility issues derived from adverse weather conditions prevented small mammal trapping on Grazed2 and Ungrazed2. Trap lines closest to the main road were located a random distance of $125 \mathrm{~m}$ from the road. Within a site, the two trap lines were separated by $100 \mathrm{~m}$ and consisted of 25 stations at $10 \mathrm{~m}$ intervals. I deployed two collapsible Sherman live traps per station totaling 50 traps per transect. Traps were baited using a mixture of oats and peanut butter. For insulation from low overnight temperatures, a handful of poly-fill was placed into each trap.

Transects of this nature are suitable for most inventory studies, and when coupled with mark recapture methodologies they can be used to obtain useful abundance information (Jones et al., 1996). Transects also yield more total captures, more individual captures and more species than grids (Pearson and Ruggiero, 2003).

Small mammal trapping occurred from November 12-17, 2009 (five nights) for a total trapping effort of 500 trap-nights per site. A day of trapping consisted of 1) checking traps and processing animals in the morning, 2) closing traps for daylight hours, and 3) reopening traps and replacing lost bait and poly-fill at dusk. I performed this work under Cal Poly IUCAC Protocol \#921 and a CDFG Volunteer Agreement. With animal in hand I recorded the species, mass (using a Pesola scale), sex, and life stage for each capture. Sex was determined by visually evaluating the anus to genitalia distance and examining the shape of the papilla. In females the distance between the clitoris and vaginal opening to the anus is proportionately less than the distance between the genital papilla to the anus in males. 
To facilitate population estimation using mark-recapture analysis, small mammals were marked for individual identification with a numbered ear tag (Model 1005-1 metal ear tag, National Band \& Tag Co., Newport, KY). Species whose ears were too small to attach an ear tag were instead marked with a series of colored dots on their bellies using a permanent marker. Following processing of each capture, animals were released no farther than five meters from the trap station of capture.

Analysis. Within a site, small mammal captures were pooled between transects for all subsequent small mammal analyses. Abundance was estimated using mark-recapture analysis. Mark-recapture analyses consisted of estimating the capture probability and population sizes of each species for closed populations using program CAPTURE (White et al., 1978). The model used to estimate capture probabilities and population sizes for each species was determined using the appropriate model option. In addition, corresponding 95\% confidence intervals were calculated for each population estimate. In addition to abundance, small mammal diversity was analyzed using species richness, Simpson's diversity index, and Sorenson's coefficient of similarity. Because trapping efforts cannot always detect all species within a specific area, I used Program EstimateS (Colwell, 2009) to estimate species richness at each site. Species richness was estimated using the Coleman rarefaction approach as well as calculating the richness estimators Chao1, Abundance-based Coverage, and Jackknife1 using 50 runs of randomization with replacement. 


\subsubsection{Habitat Structure}

\section{A. Vegetation}

Methods. I used the point intercept method on ten east-west parallel transects per site to estimate the percent coverage of different canopy and basal cover types. This method of estimating coverage is commonly utilized in grassland habitats (Elzinga et al., 1998).

The starting coordinates for each transect were determined by randomly selecting intersections on a grid overlaid on an aerial map of each site. Each grid unit was 50m x $50 \mathrm{~m}$. Transects contained 50 sampling points, each $1 \mathrm{~m}$ apart (50m total length). At each sampling point I dropped the end of a narrow metal rod from a height of a foot and the canopy cover type (grass, forb, and shrub), basal cover type (grass, forb, shrub, litter, and bare soil) and maximum canopy height was recorded. The growth form(s) that intercepted the shaft of the sampling rod determined the canopy type at a sampling point. Each growth form was recorded once per canopy sampling point. Similarly, the growth form or substrate type that intercepted the tip of the sampling rod determined the basal cover type at a sampling point. Lastly I measured the height of the tallest plant at a sampling point irrespective of its growth form (maximum canopy height).

I measured shrub abundance separately from cover using ten $10 \mathrm{~m} \times 50 \mathrm{~m}$ strip transects per site. The center of each strip transect followed the same path as the previously mentioned transects used for sampling cover and height. Within each strip transect I recorded the number of shrubs as well as the height of each individual.

Analysis. The analyses of coverage, height, shrubs and small mammal burrows were accomplished using MINITAB statistical package (Version 16.1.1, MINITAB, inc., State 
College, PA). Prior to formal hypothesis testing percent coverage was calculated for each canopy and basal coverage category using the following:

\section{$100 \mathrm{X}$ Number of hits on transect $\mathrm{X}$ \\ Total points sampled on transect $x$}

I then compared the mean coverage of each cover type between sites using parametric methods (alpha $=0.05$ ). Assumptions for parametric procedures were validated using the F-test and the Anderson-Darling test of normality. If the data failed one of these assumptions I used a Box-Cox transformation and transformed the data by using the corresponding lambda. If the data still failed one of the assumptions then I used a $\log (\mathrm{x})$ transformation. The analysis also included Tukey's multiple comparisons method when hypothesis testing resulted in a significant difference in mean coverage between sites. Another following up included comparing mean coverage between treatments (grazed vs. ungrazed) using the GLM procedure (alpha $=0.05)$. As part of the GLM procedure, I incorporated the matched pair designation as a random effect to take into account the variation attributed by the matching aspect of the study design.

In addition to coverage, mean canopy height irrespective of growth form was compared between sites. This analysis utilized the GLM procedure (alpha=0.05) and incorporated transect as a random effect.

If the data met the assumptions of normality and equal variance I used parametric methods to compare shrub abundance between sites. However, data that deviated from these assumptions warranted using non-parametric methods instead.

In addition to shrub abundance I examined the distribution of shrub height classes within and between sites using the goodness of fit test and Chi-sq test respectively (alpha $=0.05$ ). The minimum and maximum heights of the dominant shrub species (Ericameria 
linearfolia, Eriogonum fasciculatum, and Juniperus californicus) identified the shrub height categories (Hickman, 1993).

\section{B. Small Mammal Burrows}

Methods. I quantified the number and size of small mammal burrows $>1 \mathrm{~cm}$ in diameter using ten $2 \mathrm{~m} \times 50 \mathrm{~m}$ strip-transects per site. The center of each strip transect followed the same path as the prior mentioned transects used for sampling vegetation coverage and height.

Analysis. I compared small mammal burrow abundance between sites using parametric tests. However, if the data did not meet the assumptions of normality and equal variances, a transformation was attempted. I used non-parametric methods when transformed data could not meet the assumptions of normality and equal variances. Significant differences in the number of burrows between sites were investigated using a multiple comparisons test (Sequential Bonferroni's alpha).

I also compared the distribution of small mammal burrow entrance diameters between sites using the Chi squared test (alpha $=0.05$ ). Each mammal burrow was allocated to one of three burrow entrance diameter categories $(0-2 \mathrm{~cm}, 2-4 \mathrm{~cm}$ and $4-8 \mathrm{~cm})$. These classes were based upon the minimum and maximum burrow entrance diameters of Perognathus inornatus and Dipodomys heermanni (Best 1993, Kelt 1988). 


\subsection{RESULTS}

\subsection{Reptiles}

\section{A. Live trapping}

Fall (October and November 2009). Trapping arrays at both sites captured only one species, Uta stansburiana (common side-blotched lizard) (Table 3). The average \pm SE $U$. stansburiana captures per day was higher on Ungrazed1 ( $1.75 \pm 0.49$ captures/day) than Grazed1 (1.08 \pm 0.37 captures/day), however only by 1.62 times (Figure 5).

On route to checking trapping arrays at Ungrazed1, trap checkers observed $U$. stansburiana individuals as well as one individual each of the snake species Pituophis catenifer (gopher snake) and Crotalus oreganus (western rattlesnake). A shed of the snake Lampropeltis getula (California king snake) was also observed on Ungrazed1. Main Study (April and May 2010). Trapping arrays captured two species of reptile during the main study. Uta stansburiana occurred on all sites except Ungrazed2 and was the most commonly encountered reptile species, while Plestiodon gilberti (Gilbert's skink) occurred only on the two grazed sites (Table 3). Mark-recapture population estimates could not be calculated because the number of captured and marked animals of any species was insufficient.

Because $U$. stansburiana was the most commonly captured species it was the focus of the following analyses. In a comparison of the two trapping seasons, the trend in U. stansburiana captures/night between Grazed1 and Ungrazed1 was more accentuated in spring 2010. In the spring study, the average \pm SE $U$. stansburiana captures/night was 6.75 time higher on Ungrazed1 (3.58 \pm 0.35 captures/night) than Grazed1 $(0.53 \pm 0.19$ captures/night) (Figure 5). Even though average \pm SE $U$. stansburiana captures was 
lowest on Grazed2 ( $0.12 \pm 0.08$ captures/night), the pattern in abundance observed in the first matched pair was not repeated because of the lack of captures on Ungrazed2. Additional species were encountered on Grazed1 and Ungrazed2 during trap checks. A single western fence lizard (Sceloperus occidentalis) was encountered on Grazed1 while on route to checking an array, and during later vegetation surveys a shed of a gopher snake (P. catenifer) was found on Ungrazed2.

\section{B. Visual Encounter Surveys}

Fall (October and November 2009). Surveyors searched for reptiles a total of 6.09 person-hours and 8.93 person-hours on Grazed1 and Ungrazed1 respectively. Tall and dense vegetation on Ungrazed1 caused the discrepancy in effort because surveyors walked more slowly in order to accurately identify individuals.

On Grazed1 surveyors did not encounter reptile species during any of the survey occasions. In contrast, on Ungrazed1, surveyors encountered U. stansburiana most commonly and observed only one individual of both Pituophis catenifer and Crotalus oreganus (Table 3 ). The average \pm SE Ungrazed1 U. stansburiana encounter rate across sampling occasions was $5.83 \pm 1.61$ encounters/person-hour with the highest encounter rate observed on the third sampling occasion (10.55 encounters/person-hour) (Figures 6 and 7).

Air temperatures at the beginning of each survey ranged between $18 \mathrm{C}^{\circ}-23 \mathrm{C}^{\circ}$ on Grazed 1 and $16 C^{\circ}-24 C^{\circ}$ on Ungrazed1. With the exception of occasion three, sites differed by only $1 \mathrm{C}^{\circ}-2 \mathrm{C}^{\circ}$ at the beginning of each survey. Interestingly, the lowest starting air temperature $\left(16 \mathrm{C}^{\circ}\right)$ of any of the survey occasion occurred on Ungrazed 1 and 
corresponded to the highest $U$. stansburiana encounter rate (10.55 encounters/personhour) (Figure 8).

Main Study (April and May 2010). During spring 2010, visual encounter surveys were discontinued. Identification of animals could not be verified because vegetation density on Ungrazed1 impaired visibility to the point that organisms could be heard but not seen.

\subsection{Methods Comparison}

Across both field seasons, coverboards captured more reptile species than drift fences (Table 4). However, during fall 2009, visual encounter surveys detected more species including snakes (Table 3). Cover boards also had more total captures than drift fences. Across all traps of the same type, during the fall trapping season coverboards captured 2.08 captures/night and accounted for $68 \%$ of total captures while drift fences only had 0.58 captures/night. In comparison during the spring, coverboards yielded 4.24 individuals/night and accounted for $94 \%$ of total reptile captures while drift fences only captured 0.29 captures/night. Coverboards also accounted for $78 \%$ and $96 \%$ of $U$. stansburiana captures during fall and spring respectively (Table 4).

\subsection{Small Mammals}

Live Trapping. Unique capture rates by the end of the study were low on both Grazed 1 (0.05 captures/trap-night) and Ungrazed1 (0.09 captures/trap-night) irrespective of pecies

(Table 6). Two families, Cricetidae and Heteromyidae, represented the diversity of small mammals captured on both Ungrazed1 and Grazed1. On Grazed1, a total of 27 individuals were captured across four species: Peromyscus maniculatus (deer mouse), Perognathus inornatus (San Joaquin pocket mouse), Chaetodipus californicus (spiny pocket mouse), and Dipodomys heermanni (Heermann's kangaroo rat). On Grazed1, 
Peromyscus maniculatus was the most commonly captured species comprising $63 \%$ of unique captures (Table 6). Chaetodipus californicus, Dipodomys heermanni and Perognathus inornatus comprised the remaining 37\% of unique captures (Figure 9 and Table 6).

On Ungrazed1 I captured a total of 47 individuals of five species: Peromyscus maniculatus, Perognathus inornatus, Chaetodipus californicus, D. heermanni and Reithrodontomys megalotus (western harvest mouse). Chaetodipus californicus and Peromyscus maniculatus represented the most commonly captured species on Ungrazed1, accounting for $42 \%$ and $40 \%$ of unique captures respectively (Table 6 ). Through the entire study period, one R. megalotus individual was captured. D. heermanni and Perognathus inornatus comprised a small portion of captures consisting of $16 \%$ of unique captures (Figure 9 and Table 6).

Three best models of capture probability for population estimation were selected by program CAPTURE and varied among species and sites (Table 7). Model M0 was selected for the grazed Chaetodipus californicus, Perognathus inornatus and Peromyscus maniculatus populations as well as the ungrazed D. heermanni population. Model Mth (Chao's estimator) was selected for the ungrazed Chaetodipus californicus and grazed $D$. heermanni populations. The estimator chosen for model Mt (Darroch's estimator) was selected for both the grazed and ungrazed Peromyscus maniculatus populations.

Capture probabilities produced by these models also varied among species. Capture probabilities for Chaetodipus californicus and Perognathus inornatus were lower than D. heermanni and Peromyscus maniculatus at both sites (Table 7). Ungrazed capture probability was highest for Peromyscus maniculatus (0.82) followed by $D$. 
heermanni, Chaetodipus californicus, and Perognathus inornatus (Table 7).

Contrastingly, grazed capture probability was highest for Dipodomys heermanni (0.75) followed by Peromyscus maniculatus, Perognathus inornatus, and lastly Chaetodipus californicus (Table 7).

Capture probability adjusted population estimates varied across species (Figure 10). Population estimates only differed by $0-1$ individuals across all species and sites except for the ungrazed Chaetodipus californicus and grazed Peromyscus maniculatus populations whose estimates differed from the unique capture rate by 14 and 3 individuals respectively (Figure 10 and Table 7). However the 95\% confidence intervals for Chaetodipus californicus, D. heermanni and Peromyscus maniculatus indicated that population estimates could be much greater. For example, Chaetodipus californicus population estimates on the grazed and ungrazed sites could be as high as 11 and 69 individuals respectively, in which case, the population estimates would be 2.2 and 3.6 times greater than the unique captures.

Diversity. Both observed species richness and Simpson's index of evenness was higher on Ungrazed 1 than Grazed1, but only by a single species (Table 6). The species composition of the two communities was very similar (Sorenson's index of community similarity $=0.89$ ), sharing all species except $R$. megalotus which was only at Ungrazed1 .

The rate at which Grazed 1 accumulated species was higher than Ungrazed1

(Figure 11). The Grazed1 Coleman rarefaction curve clearly begins to level off while the Ungrazed 1 curve did not reach a clear asymptote.

Estimated richness was similar to observed species richness across all estimators (Table 6). On both sites, the difference between richness estimators and the observed 
richness on Grazed 1 and Ungrazed 1 ranged from 0 to 0.33 species and -0.26 to 0.18 species respectively. The average of the three richness estimators differed from the observed richness on Grazed 1 and Ungrazed 1 by 0.16 and 0.01 species respectively. Thus it was unlikely that other nocturnal small mammal species were present but not detected.

\subsection{Habitat Structure}

Results for plant physiognomy, shrub density, and small mammal hole density was based on ten transects per site except for Grazed1 where missing data resulted in data for nine transects.

\section{A. Vegetation}

Physiognomy. Average forb canopy cover significantly differed between sites ( $\mathrm{F}=10.11$, $\mathrm{df}=3, \mathrm{p}<0.001$, ANOVA). Tukey's multiple comparison of average forb canopy coverage identified two groups of sites. Average forb canopy coverage was significantly

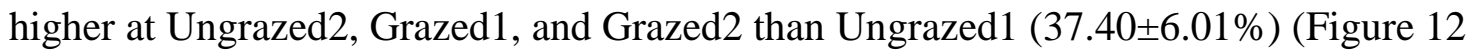
and Table 8). Interestingly, U. stansburiana abundance was also highest at Ungrazed1. There was also a significant difference between Grazed and Ungrazed treatments, but there was also a significant matched pair effect indicating site level variations in forb canopy coverage $(\mathrm{F}=4.23, \mathrm{df}=1, \mathrm{p}=0.05, \mathrm{GLM} /$ matched pair effect $\mathrm{F}=16.58, \mathrm{df}=1$, $\mathrm{p}<0.001)$. Average grass canopy coverage did not differ between sites $(\mathrm{F}=2.26, \mathrm{df}=3$, $\mathrm{p}=0.10$, ANOVA: second power transformation). Shrub canopy coverage represented only $<5 \%$ of the total canopy coverage on Ungrazed1 and $0 \%$ on Grazed1.

Average basal forb coverage was significantly different between sites $(\mathrm{F}=10.81$, $\mathrm{df}=3, \mathrm{p}<0.001$, ANOVA: no transformation). Tukey's multiple comparison of basal forb 
percent coverage identified two groups of sites. Average basal forb coverage was significantly lower at Grazed1 and Ungrazed1 than Grazed2 and Ungrazed2 (Figure 13 and Table 8). These groups were consistent with elevation differences between site matched pairs. There was also no significant difference between Grazed and Ungrazed treatments, but there was a significant matched pair effect $(\mathrm{F}=0.04, \mathrm{df}=1, \mathrm{p}=0.85$, GLM / matched pair effect $\mathrm{F}=33.18, \mathrm{df}=1, \mathrm{p}<0.001$ ) Average basal grass coverage was not significantly different between sites $(\mathrm{F}=2.04, \mathrm{df}=3, \mathrm{p}=0.13$, ANOVA: $\log$ transformation). Average litter coverage was not significantly different between sites $(\mathrm{F}=0.71, \mathrm{df}=3, \mathrm{p}=0.55$, ANOVA: square root transformation).

Average bare soil coverage was significantly different between sites $(\mathrm{F}=5.67$, $\mathrm{df}=3, \mathrm{p}=0.003$, ANOVA: square root transformation). Tukey's multiple comparison of basal forb coverage identified three groups of sites (Group 1: Grazed1 and Ungrazed1| Group 2: Grazed2 and Ungrazed2 | Group 3: Ungrazed1 and Grazed2) (Figure 13 and Table 8). There was no significant difference in bare soil coverage between Grazed and Ungrazed treatments, but there was a significant matched pair effect $(\mathrm{F}=0.49, \mathrm{df}=1$, $\mathrm{p}=0.49$, GLM: $\log$ base 10 transformation/ matched pair effect $\mathrm{F}=16.19, \mathrm{df}=1, \mathrm{p}<.001$ ). The matched pair effect was illustrated by a higher average bare soil coverage on Grazed1 and Ungrazed1 than Grazed2 and Ungrazed2 (Figure 13 and Table 8). Because subsamples within each transect cannot be deemed independent, for the purposes of this study "average canopy height" for each site was defined by averaging height across subsamples within each transects and then averaging once again between transects. Subsamples where height was zero were excluded from analysis because of the lack of additional information gained. Average canopy height \pm SE tended to be higher on 
Ungrazed1 $(42.04 \pm 3.47 \mathrm{~cm})$ and Ungrazed2 $(36.89 \pm 2.28 \mathrm{~cm})$ than Grazed1

$(32.75 \pm 2.84 \mathrm{~cm})$ and Grazed2 $(30.47 \pm 2.58 \mathrm{~cm})$ (Figure 14). However, there was no significant difference in canopy height between sites, but there was significant variation between individual transects (Site (main effect): $F=2.2, \mathrm{df}=3, \mathrm{p}=0.12$, GLM: square root transformation; Transect (random effect): $\mathrm{F}=7.94, \mathrm{df}=35, \mathrm{p}<.001$ ). MINITAB computed an approximate F-value for the transect effect because the effect of transect was very small.

Shrubs. Shrubs were found only on Grazed1 and Ungrazed1. This was not an artifact of random sampling considering shrubs were not visible on the entirety of Grazed2 and Ungrazed2. Shrub density was low on both sites (Grazed1: $<0.001$ shrubs $/ \mathrm{m}^{2}$ and Ungrazed1: 1.02 shrubs $/ \mathrm{m}^{2}$ ). Shrub counts were zero inflated and violated parametric assumptions. After a square root transformation, the data still violated parametric assumptions so non-parametric methods were used. The average \pm SE shrubs/transect was higher on Ungrazed1 (4.1 \pm 2.3 shrubs/transect) than Grazed1 ( $0.47 \pm 0.42$ shrubs/transect) (Figure 15), however shrub counts did not differ significantly between sites ( $\mathrm{W}=71, \mathrm{p}=$ 0.09 adj for ties, Mann-Whitney test).

There was not a significant association between site and shrub height class $\left(\chi^{2}=\right.$ 1.52, $\mathrm{df}=2, \mathrm{p}=0.47$,) (Figure 16). Grazed1 had a total of nine shrubs across two of nine strip transects surveyed, with 8 of the shrubs found on one strip transect. On Grazed1, only shrubs less than $40 \mathrm{~cm}$ and shrubs $40-100 \mathrm{~cm}$ tall were encountered and comprised similar contributions, $45 \%$ and $55 \%$ respectively, to total number of shrubs. Ungrazed1 had a total of 82 shrubs across six of the ten transects surveyed. Half of the shrubs were found in one transect, a second transect accounted for $28 \%$ of the shrubs, and 
the remaining $22 \%$ of shrubs were dispersed among the other 4 transects. All three height classes were encountered, but shrubs were not equally distributed among those classes $\left(\chi^{2}=51.02, \mathrm{df}=2, \mathrm{p}\right.$-value $\left.=<.001\right)$. Shrubs between 40 and $100 \mathrm{~cm}$ comprised the majority of encountered shrubs followed by shrubs less than $40 \mathrm{~cm}$ and shrubs greater than $100 \mathrm{~cm}$ tall (Figure 16).

\section{B. Small Mammal Burrows}

Small mammal burrows were detected on all sites. Ungrazed1 had the highest average \pm SE number of holes/transect (4.00 \pm 2.21 holes/transect) (Figure 17). Also, average \pm SE holes/transect was higher on Grazed1 (3.56 \pm 1.13 holes/transect) and

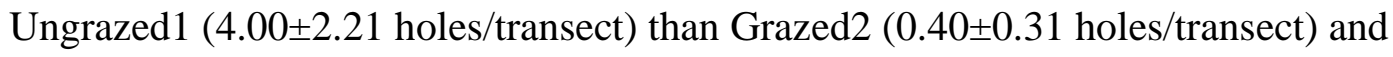
Ungrazed2 (1.10 \pm 0.59 holes/transect) (Figure 17). However, small mammal burrows were not evenly distributed on the landscape. For instance on Ungrazed $158 \%$ of the total burrows detected were found on a single transect. Thus hole counts were zero inflated and violated parametric assumptions. A square root transformation of the data did not satisfy the assumptions of parametric tests so a non-parametric method was used to compare burrow counts. Burrow abundance differed significantly between sites $(\mathrm{H}=$ 12.99, df=3, p-value=0.005 - adj for ties, Kruskall-Wallace test). The Kruskall-Wallace test was applied to all combinations of sites for multiple comparisons and used the sequential Bonferroni method. Grazed1 was significantly different from both Grazed2 $(\mathrm{H}=11.17, \mathrm{df}=1, \mathrm{p}=0.001$, alpha $=0.008)$ and Ungrazed $2(\mathrm{H}=6.12, \mathrm{df}=1, \mathrm{p}=0.01$, alpha $=$ $0.01)$. 
Other combinations of sites were not significantly different from one another. There was an association between site and entrance diameter $\left(\chi^{2}=20.18, \mathrm{df}=9, \mathrm{p}\right.$ value $=0.02)$ (Table 9). The number of burrows observed on Ungrazed 2 consistantly deviated from the expected value across all burrow diameter classes (Table 9). On Ungrazed2, the number of observed burrows was 4.76 times greater and 2.0 times greater than expected values for burrow diameters of $<2 \mathrm{~cm}$ and $2-4 \mathrm{~cm}$ respectively. The observed number of burrows was also 0.4 times less than the expected values for burrow diameters of $4-8 \mathrm{~cm}$ on the same site. There however, was no association between entrance diameter and management $\left(\chi^{2}=2.12, \mathrm{df}=3, \mathrm{p}\right.$-value $=0.548, \chi^{2}$ test $)$. Grazed 2 and Ungrazed 2 contributed the greatest percentage of the total chi-square value, $27 \%$ and $66 \%$ respectively.

On Grazed1 and Ungrazed1 burrow size classes were not equally distributed (Grazed1: $\chi^{2}=17.25, \mathrm{df}=3, \mathrm{p}$-value $=.001 ;$ Ungrazed1: $\chi^{2}=19.4, \mathrm{df}=3, \mathrm{p}$-value $=<.001$, Goodness of fit test). On Grazed1, holes that were $<2 \mathrm{~cm}$ and $4-8 \mathrm{~cm}$ in diameter contributed the most to the total chi-square, $36 \%$ and $46 \%$ respectively (Figure 18). On Ungrazed1, holes that were $<2 \mathrm{~cm}$ and $4-8 \mathrm{~cm}$ diameter also contributed the most to the total chi-square, $42 \%$ and $42 \%$ respectively. Entrance diameter class distributions were similar between Grazed 1 and Ungrazed 1 and holes that were $4-8 \mathrm{~cm}$ and $2-4 \mathrm{~cm}$ in diameter composed the greatest proportion of total holes at both Grazed1 and Ungrazed1. Distribution of burrow entrance diameters was more similar between sites of the same elevation. 


\subsection{DISCUSSION}

\subsection{Reptiles}

The prediction that species richness and abundance would be lower on the grazed sites than ungrazed sites was not supported. During the fall 2009 season species richness was greater on Ungrazed1, but the opposite pattern was observed during the spring 2010 season. The discontinuation of visual encounter surveys during spring 2010 may have confounded this result considering visual encounter surveys were able to detect species that live trapping could not in fall 2009.

Plestiodon gilberti was caught only on the two grazed sites and at very low numbers. Gilbert's skink is a generalist occurring in grassland, salt flats, high desert, open chaparral, pinon juniper woodlands, and open pine forests especially near rocks and creeks and springs (Stebbins, 2003). Based upon Gilbert's skink ecology I would expect them to be present at both grazed and ungrazed sites, but they were not. Further study of its microhabitat requirements may provide information as to why they were found where they were.

Even though $U$. stansburiana was less abundant at the Grazed1 site than Ungrazed 1 in both field seasons, the prediction of lower abundance on grazed sites overall was not supported. Also, species richness was comparable between grazed and ungrazed sites and did not support the prediction of greater species richness on ungrazed sites. During spring 2010, statistical analysis failed to show differences in species richness and abundance between grazed and ungrazed treatments because of the large variation observed between sites within the same treatment. Other studies of grazing did not produce the same patterns. Bock et al. (1990) examined the abundance of the 
bunchgrass lizard (Sceloporus scalaris slavini) across heavily grazed and ungrazed treatments in Santa Cruz County, Arizona. Relative abundance of bunchgrass lizards was greater in the ungrazed treatment than the grazed treatment. Also Beever and Brussard (2004) found greater reptile diversity on average in areas without horse grazing than areas with horse grazing. Seven of nine reptile species were more abundant in areas unoccupied by horses. The variation observed in the current study may be explained by the high levels of spatial heterogeneity found in California valley grasslands. Within a single growing season California valley grasslands exhibit spatial variation in both plant biomass and species composition from site to site (Bartolome et al., 2007). In turn, the animal communities exhibit the same spatial heterogeneity. Future studies of grazing in grasslands would require a design that can adequately address spatial heterogeneity. A greater number of study sites would be required to take into account the variation in reptile species richness and abundance due to spatial heterogeneity (Morrison et al., 2001).

Reptile captures were also inconsistent between study seasons. Environmental conditions were also not the same between seasons and likely contributed to the inconsistency. Vegetation structure differed on the grazed pasture depending upon whether cattle were present. When cattle were present in 2009, the landscape consisted almost exclusively of bare soil. When cattle were removed, in 2010, bare soil cover lessened and the amount of vegetative cover increased. Future studies of grazing that occur over many seasons would need to ensure that grazing treatments are consistent between seasons. 


\subsection{Methods Comparison}

Each method had both advantages and disadvantages. An examination of the attributes of these three reptile sampling techniques revealed each method's benefits and pitfalls (Table 5). Pitfall traps, though costly and effort intensive to construct and maintain, allow researchers to collect more data per detection such as SVL, mass, age, and sex than other methods because animals can be handled. Coverboards and visual encounter surveys are relatively cheap to deploy and result in a high number of captures, but the amount of data gleaned from each capture is restricted to counts and species identification. However, because of the diversity observed in sexual, seasonal, morphological, behavioral, habitat preference, activity, and life history traits in reptile species assemblages it is necessary to deploy multiple survey methods to adequately survey a community. For instance, reptiles are usually sampled using coverboards and visual encounter surveys during the day time and would not as likely detect nocturnal species. However drift fences with live traps can sample nocturnal species because once captured the animals would stay in the traps until a researcher can to remove them. The majority of studies that involve sampling snake populations only utilize one method and are probably biased towards capturing a subset of the snake community (Kjoss and Litvaitis, 2001).

Fitch (1992) examined the relative success between incidental encounters, live trapping using funnel traps and artificial cover for sampling snake populations. Each method differed in overall and species specific capture success. Cover boards caught more snakes than any other method. Species specific capture success also differed across methods. Cover boards had greater success at capturing small and secretive snake 
species while live trapping was most productive at capturing medium sized snake species (0.4-1m snout-vent length) (Corn and Bury, 1990; Fitch, 1992).

The importance of using multiple methods to sample communities was also illustrated in the current study. Even though during the fall 2009 field season visual encounter surveys did not detect reptiles on Grazed1 the live trapping arrays did. I attribute this difference to the lack of cover during that grazing season. Animals that were present used the arrays since there was virtually no other available cover. Thus these methods complement each other, further illustrating the need for multiple methods when conducting community level research.

Live trapping arrays did not capture snakes during both live trapping seasons. Snake densities were probably low on sites thus decreasing the probability that individuals would intercept the drift fences or cover boards. In situations like this, both longer fences and more trapping days would increase detection probability. The current study indicated why it is so hard to sample for snakes and that innovative methods for capturing them are of utmost importance if they are to be used as a study organism or ecological indicator.

\subsection{Small Mammals}

The results of the small mammal study did support the prediction that species richness and abundance would be lower on grazed sites than ungrazed sites. Most notably, R. megalotus was only detected on Ungrazed1 and Chaetodipus californicus abundance was much greater on Ungrazed1 than Grazed1. Like the current study, Reynolds and Trost (1980) also observed lower small mammal species richness in grazed areas. 
However, species composition between Grazed1 and Ungrazed1 had a high degree of similarity, sharing all small mammal species except for $R$. megalotus which was found on Ungrazed1. Since Grazed1 was actively grazed during the time small mammal trapping occurred, $R$. megalotus was more likely to be detected only on Ungrazed1. Reithrodontomys megalotus is typical of overgrown and weedy pastures where they can build above ground nests made of vegetation (Webster and Jones, 1982). With nesting material removed as a direct impact by cattle it was unlikely that $R$. megalotus could establish on Grazed1. Other than R. megalotus, Chaetodipus californicus population size was negatively affected by grazing. Chaetodipus californicus is associated with shrubby landscapes (Verts and Carroway, 1998). Although not explicitly observed in this study, the lack of shrubs on the grazed pasture may have arisen from cattle trampling. The reduction in shrub density by cattle would ultimately result in lower Chaetodipus californicus abundances as seen on Grazed1.

\subsection{Habitat Structure}

There was not enough evidence to support the prediction that vegetation height, cover, shrub density and small mammal burrow density would be less on grazed sites than ungrazed sites. Site effects at the matched pair level were more evident than treatment effects for all basal coverage types and small mammal burrow density. This means that there was more within treatment variation than between treatment variation. The lack of a difference could be attributed to several factors. One of these is the timing in which the pastures were grazed. During fall 2009 active grazing occurred and the difference in habitat structure between treatments was visually evident. However, during spring 2010, when habitat structure was quantified, cattle were not present. Without 
grazing pressures the annual grasses and forbs returned and were comparable in height and coverage to the ungrazed pasture. As a result, it may be beneficial to limit data collection to the grazing or non-grazing seasons. Combining the two adds extraneous factors that will confound the effects of grazing. Another possible factor is that spatial heterogeneity commonly found in grasslands produced the results that were observed. California valley grasslands exhibit enormous amounts of spatial heterogeneity in biomass and species composition from site to site within the same growing season (Bartolome et al., 2007).

\subsection{Conclusions}

In an attempt to adequately sample the reptile community, this study deployed multiple methods to encompass the variations in species ecology. Each sampling protocol had costs and benefits depending upon the research objectives. The current study also addressed the difficulty in attaining abundance. Traditionally abundance is quantified using indices such as relative abundance and captures per unit effort. These methods however do not take into the number of animals that are inevitably not observed and are actually underestimating abundance. It is imperative to use capture probabilities when estimating population sizes especially when doing comparisons and is a reason that trapping methodologies are more useful than methods that can only estimate relative abundances.

Even though spatial heterogeneity and timing relatively to grazing cycles made it difficult to ascertain treatment affects on reptile and small mammal species richness and abundance this study raises some possible impacts of grazing on $U$. stansburiana. Since herbivory and trampling from cattle grazing tends to leave the landscape at early seral 
stages, species which rely on shrub cover, such as Chaetodipus californicus, may be directly reduced in abundance. Heteromyid species such as Chaetodipus californicus are regarded as ecosystem engineers and create their own burrows which are used by other animals, and this is the pattern that seems to occur in this study. Therefore, lower numbers of Chaetodipus could result in lower numbers of holes and decreasing $U$. stansburiana abundance. However, this proposed cascade assumes that rocky outcrops are absent. U. stansburiana is highly associated with rocky outcrops and uses them as refugia and for thermoregulation (Davis and Verbeek, 1972). If rocky outcrops were present, small mammal hole density may become irrelevant. This proposed cascade also assumes that Uta stansburiana are generalists in regards to burrow use. If not, Chaetodipus hole density may be irrelevant. Nonetheless, in order to study the effects of grazing to create generalized conclusions, one must address the sources of variation encountered in this study. These sources of variation include spatial and temporal heterogeneity as well as variation derived from study design. Some methods to reduce these effects include increasing the number of replicates and limiting data collection to a standard part of the grazing cycle. In addition when sampling reptiles one must determine appropriate spatial scales. For instance, because of differences in home range, spatial scales that are adequate to sample lizards may be too small to sample for snakes. 


\section{CHAPTER II}

Habitat Preference and Utilization of the Common Side-Blotched Lizard (Uta stansburiana) in a San Joaquin Valley Grassland

\subsection{INTRODUCTION}

The common side blotched lizard (Uta stanburiana; family Phrynosomatidae) is one of the most abundant lizards in the arid and semi-arid southwest. Side-blotched lizards are geographically widespread occurring from Central Washington to Baja, Mexico and from the Pacific coast to western Colorado and western Texas (Stebbins, 2003). Even within small portions of its range side-blotched lizards inhabit a variety of habitats. For instance, within Baja California, side-blotched lizards occupy all four faunal zones (Savage, 1960). Side-blotched lizards are found in a variety of macro and microhabitats including rocky outcrops, desert washes, sand dunes, sage brush flats, and grasslands (Tinkle, 1967). However, species with widespread ranges that occur in a variety of habitats may not necessary show the same microhabitat habitat preferences at all locations due to the presence or absence of particular resources. Habitat preference is determined by resource availability, predation risk, physical constraints, mating opportunities and in the case of small ectotherms, thermal quality (Diaz, 1997). This study focuses on identifying and quantifying the microhabitat preferences of the common side-blotched lizard in a San Joaquin Valley annual grassland. 


\subsection{STUDY AREA}

This study was conducted at the same location as in Chapter 1 . Refer to Chapter 1 for information regarding the study area. 


\subsection{METHODS}

Live Trapping. This study utilized the same arrays and capture data collected from pitfall trapping and coverboard methods conducted in Chapter 1 during spring of 2010 to determine U. stansburiana presence. Refer to Chapter 1 for study design and array layout.

Array Covariates. In May 2010 habitat covariates were measured at array locations in order to model $U$. stansburiana presence. Covariates included those that pertain to management, aspect, shrub presence, slope, burrow abundance, vegetation canopy height, and percent ground coverage. Table 10 lists and describes the method for collection of the aforementioned habitat covariates. Habitat covariates were either recorded at the center of each array or within eight $1 \mathrm{~m}^{2}$ quadrats (each cardinal direction contained 2 quadrats, one located at $4 \mathrm{~m}$ and the other $6 \mathrm{~m}$ from array center). Covariates measured within $1 \mathrm{~m}^{2}$ quadrats were averaged to produce a single value for each array.

Analysis. I used logistic regression to assess the relationship between $U$. stansburiana presence and the habitat covariates. Presence was modeled instead of abundance because not all individuals could be individually identified thus double counting could potentially occur. Likewise, an approach using mark-recapture based population estimates was not possible. Slope, average forb height, average grass height, average bare soil coverage, average grass coverage and average forb coverage for each array were calculated as the average across quadrats.

Each individual covariate was analyzed using logistic regression in MINITAB statistical package (Version 16.1.1, MINITAB, inc., State College, PA). Variables whose likelihood ratio test p-value was $>0.25$ were removed from subsequent analyses (Hosmer 
and Lemeshow, 2000). The remaining variables were tested for correlation by compiling a pairwise correlation matrix also generated in MINITAB. Pairs of covariates that were highly correlated (Pearson's correlation coefficient was $>60 \%$ and p-value $<0.05$ ) were compared by their likelihood ratio test p-values, and the variable of the pair with the higher p-value was removed from subsequent analyses (Hosmer and Lemeshow, 2000). .

For all combinations of the remaining variables, logistic regression was performed using proc logistic in SAS (Version 9.2, SAS institute, Cary, NC) and the resulting AIC values calculated. Because the ratio of samples to parameters was $<40$, AICc was used to compare models and account for small sample size (Burnham and Anderson, 1998). 


\subsection{RESULTS}

Uta stansburiana was detected at 7 of 20 arrays over 17 days of trapping. Of the arrays where $U$. stansburiana was present, 3 were on the grazed pasture and 4 were on the ungrazed pasture.

The covariates management, aspect, forb height, forb cover, and slope were excluded from subsequent analyses because their likelihood ratio test p-values from univariate logistic regressions were >0.25 (Hosmer and Lemeshow, 2000) (Table 11). Shrub presence resulted in a quasi-complete separation of data points, meaning that shrub presence showed a near perfect relationship with $U$. stansburiana presence. However, logistic regression cannot handle this type of situation and the shrub covariate was not included in subsequent analyses. Shrubs were present at three arrays all of which were positive for the presence of $U$. stansburiana. Only one shrub fell within each $10 \mathrm{~m}$ radius. Therefore, though shrub category cannot be incorporated into the multivariate model, it must be accepted as positively correlated with Uta presence.

Variables whose likelihood ratio p-value was $<0.25$ included one structural component (holes), one canopy component (grass height), and two coverage components (grass cover and bare soil cover) (Table 11). The average \pm SE number of holes at arrays where $U$. stansburiana was present $(1.29 \pm 0.52$ holes $)$ was 3.4 times greater than at arrays where $U$. stansburiana was not detected (0.38 \pm 0.18 holes) (Figure 19). The maximum number of holes at an array was three and occurred at two of seven arrays where $U$. stansburiana was present. Grass height was $10.46 \mathrm{~cm}$ shorter at arrays where $U$. stansburiana was present (Figure 20). Grass cover was 1.7 times greater at arrays where 
Uta stansburiana was not detected (Figure 20), and bare soil coverage was 1.8 times greater at arrays where $U$. stansburiana was present (Figure 21).

Both grass height and grass cover were $>60 \%$ correlated with bare soil cover as well as with each other (Table 12). Based on their univariate likelihood ratio p-values, grass height and grass cover were excluded from subsequent analyses.

Ultimately, three possible logistic regression models were generated to predict side-blotched lizard presence at arrays. These models were:

1) Bare soil cover

2) Holes

3) Bare soil cover + Holes

Model Bare soil cover had the lowest AICc value (28.119) and carried 0.54 of the total model likelihood followed by Holes and lastly Bare soil cover + Holes (Table 13). There was model uncertainty since $\Delta \mathrm{AICc}$ values for models Bare soil cover + Holes and Holes were $<2$. In all models all coefficients were positive and the equations for each model are as follows:

$$
\begin{aligned}
& \operatorname{logit}(\mathrm{p})=-2.720+0.058 \pm 0.028(\text { Bare soil }) \\
& \operatorname{logit}(\mathrm{p})=-1.330+0.932 \pm 0.538(\text { Holes }) \\
& \operatorname{logit}(\mathrm{p})=-2.858+0.048 \pm 0.028(\text { Bare soil })+0.9316 \pm 0.601(\text { Holes })
\end{aligned}
$$




\section{$\underline{\text { 5.0 DISCUSSION }}$}

Microhabitat utilizations by $U$. stansburiana differed between this study and the majority of other studies conducted within other geographic areas within its range. This study suggests that greater bare soil coverage and greater burrow density were positively associated with microhabitat characteristics in determining $U$. stansburiana presence. In addition, shrub presence exhibited a quasi-complete separation of data points and although it was not further modeled using logistic regression, this study suggests that this covariate is an important factor as it near perfectly associated positively with $U$. stansburiana presence. Similarly, Baltosser and Best (1990) studied habitat association of Uta stansburiana at a site in the southwestern New Mexico desert. U. stansburiana occurred in areas of relatively abundant vegetation and ground cover as well as areas of higher shrub density. In addition, bare ground cover occurred in upwards of 20-40\%. Contrasting to the current study, Davis and Verbeek (1972) found that $U$. stansburiana in coastal Monterey County, California avoided both wooded and heavily shaded areas and exclusively utilized rocky outcrops. The current study took place at a site that lacked rocky outcrops. However, the current study does have some limited generality as do many studies of habitat utilization. Since the current study only occurred within an extremely small portion of $U$. stansburiana's range in annual grasslands, habitat utilization cannot be generalized. Instead this study can only provide additional information regarding important habitat components.

For reptiles, habitat structure acts as thermoregulatory resources and sources of refugia. The thermal quality of the habitats occupied by lizards can influence foraging time, mate acquisition and predator avoidance (Diaz, 1997). Uta stansburiana 
thermoregulates by shuttling between shaded and unshaded locations in an effort to maintain an optimal activity temperature. Common forms of shade include burrows, debris, shrubs, rocky outcrops and vegetative cover, and common sources of thermal structure include open ground, rocks and woody debris. However these thermoregulatory resources may not be distributed equally throughout an organism's geographic range. Since this study area lacked both rocky outcrops and woody debris, bare soil then becomes an important thermal resource. Also because of the lack of rocky outcrops to retreat into, $U$. stansburiana must instead utilize burrows, shrubs and vegetative cover (grasses and forbs) to find shade. Davis and Verbeek (1972) observed U. stansburiana shuttling between shaded and unshaded portions of rock outcrops throughout the day to thermoregulate. If temperatures were too high or rocks were fully sun exposed, the lizards retreated beneath rocks or to nearby rodent burrows.

Because U. stansburiana are food sources for many species of snakes, lizards, and birds, predator avoidance strategies become important for survival (Tinkle, 1967). Structural components such as shrubs, vegetative cover, rocky outcrops and rodent burrows are important refugia. Within the pastures sampled during the current study, burrows and shrubs constituted the main source of refuge from predation for $U$. stansburiana. As I was travelling among trapping arrays, the U. stansburiana that were disturbed commonly sought shelter under shrubs or escaped into nearby burrows.

Other species of lizards found in the San Joaquin Valley commonly use burrows as refugia. The population density of blunt nosed leopard lizards (Gambelia sila), which within its range commonly co-occurs with $U$. stansburiana, increases with increasing small mammal burrow density. Adult blunt nosed leopard lizards commonly use these 
structures for safety (Montanucci, 1965). Also, Gilbert's skink (Plestiodon gilberti), a species which co-occurs with $U$. stansburiana, readily took shelter in kangaroo rat (Dipodomys spp.) burrows (Montanucci, 1968). Burrows can also be important hibernacula in winter and spring for $U$. stansburiana allowing for shelter from low temperatures and precipitation (Montanucci, 1968).

Quantifying basic ecological information is important to managing populations by identifying important resources and habitat components utilized by a given species within a given geographic area. It may be erroneous to generalize across the entirety of a species' range especially in lizard species that have large geographic ranges encompassing multiple habitat types. Resources can be more or less important, given the presence of other resources. As shown by this study, the focus on lizard microhabitat utilization should be on environmental characteristics that provide thermal structure and refugia. 


\section{BIBLIOGRAPHY}

Alderfer, R.B. and R.R. Robinson. 1949. Runoff from pastures in relation to grazing intensity and soil compaction. Journal of the American Society of Agronomy. Vol. 39:948-958.

Baltosser, William H. and Troy L. Best. 1990. Seasonal occurrence and habitat utilization by lizards in southwestern New Mexico. The Southwestern Naturalist. Vol. 35, No. 4: 377-384.

Bartolome, James W., W. James Barry, Tom Griggs, and Peter Hopkinson 2007. Valley Grassland. Pages 371-397 in M. G. Barbour, Todd Keeler-Wolf, and Allan A. Schoenherr (eds.), Terrestrial Vegetation of California Third Edition. University of California Press.

Beever, Erik A. and Peter F. Brussard. 2004. Community and landscape level responses of reptile and small mammals to feral horse grazing in the Great Basin. Journal of Arid Environments. Vol. 59: 271-297.

Belnap, J., K.T. Harper and S.D. Warren. 1994. Surface disturbance of cryptobiotic soil crusts: nitrogenase activity, chlorophyll content, and chrlorophyll degredation. Arid Soil Research and Rehabilitation. Vol. 8:1-8.

Best, T.L. 1993. Perognathus inornatus. Mammalian Species. 450:1-5.

Bock, Carl E., Hobart M. Smith and Jane H. Bock. 1990. The effect of livestock grazing upon abundance of the lizard, Sceloporus scolaris, in southeastern Arizona. Journal of Herpetology. Vol. 24 No. 4: 445-446.

Brown, James H. and William McDonald. 1995. Livestock grazing and conservation on southwestern rangelands. Conservation Biology. Vol. 9 No. 6: 1644-1647.

Burnham, K. P., and D. R. Anderson. 2002. Model selection and multimodel inference: a practical information-theoretic approach. 2nd Edition. Springer-Verlag, New York, New York, USA.

Busack, Stephen D. and R. Bruce Bury. 1974. Some effects of off-road vehicles and sheep grazing on lizard populations in the Mojave Desert. Biological Conservation. Vol 6 No. 3: 179-183.

Colwell, R. K. 2009. EstimateS: Statistical estimation of species richness and shared species from samples. Version 8.2.

Corn, P.S. and Bury, R.B. 1990. Sampling methods for terrestrial amphibians and reptiles. In A.C. Carey and L. F. Ruggiero (eds.), Wildlife-Habitat Relationships: Sampling Procedures for Pacific Northwest Vertebrates, pp. 1-28. U.S. Dept. Agri. For. Serv., Gen. Tech. Rep. PNW-GTR-256. 
Council for Agricultural Science and Technology. 1974. Livestock grazing on federal lands in the 11 western states. Journal of Range Management. Vol. 27:171-181.

Crump, Martha L. and Norman J. Scott, Jr. 1994. Visual encounter surveys. Pages 8492 In: W. Ronald Heyer, Maureen A. Donnelly, Roy W. McDiarmid, Lee-Ann C. Hayek, and Mercedes S.Foster (eds.) Measuring and Monitoring Biological Diversity. Standard Methods for Amphibians. Smithsonian Institution Press.

Davis, John and Nicolaas A. M. Verbeek.1972. Habitat preferences and the distribution of Uta stansburiana and Sceloporus occidentalis in coastal California. Copeia. No. 4: 643-649.

Diaz, J.A. 1997. Ecological correlates of the thermal quality of an ectotherm's habitat: A comparison between two temperate lizard populations. Functional Ecology. Vol. 11, No. 1: 79-89.

Duff, D.A. 1979. Riparian habitat recovery on Big Creek, Rich County, Utah-a summary of 8 years of study. In Proceedings of the forum--grazing and riparianstream ecosystems] Denver, Colorado, November 30, 1978] Trout Unlimited Inc., Vienna, Vir.

Elzinga, C.L., D.W. Salzer, and J.W. Willoughby. 1998. Measuring and monitoring plant populations. Bureau of Land Management,Technical Reference 1730-1,Denver, Colorado, USA.

Fellers, Gary M. and Charles A. Drost. 1994. Sampling using artificial cover. Pages 146-150. In: W. Ronald Heyer, Maureen A. Donnelly, Roy W. McDiarmid, LeeAnn C. Hayek, and Mercedes S.Foster (eds.) Measuring and Monitoring Biological Diversity. Standard Methods for Amphibians. Smithsonian Institution Press.

Fitch, Henry S. 1987. Collecting and life-history techniques. Pages 143-164 in Richard A. Siegal, Joseph T. Collins, Susan S. Novak. Snakes: Ecology and Evolutionary Biology. Macmillan Publishing Company. New York.

Fitch, Henry S. 1992. Methods of sampling snake populations and their relative success. Herpetological Review. 23: 17-19.

Fleischner, Thomas L. 1994. Ecological risks of livestock grazing in western North America. Conservation Biology. Vol. 8 No. 3: 629-644.

Franklin, J.F., K. Cromack Jr., W. Denison, A. McKee, C. Maser, J. Sedell, F. Swanson and G. Juday, 1981. Ecological characteristics of old-growth Douglas-fir forests. General Technical Report PNW-118. U.S. Forest Service, Pacific Northwest Forest and Range Experiment Station, Portland Oregon. 
Germano, Davis J., Galen B. Rathbun and Larry R. Saslaw. 2001. Managing exotic grasses and conserving declining species. Wildlife Society Bulletin. Vol. 29, No. 2, pp. 551-559

Glinski, R.L. 1977. Regeneration and distribution of sycamores and cottonwood trees along Sonoita Creek, Santa Cruz County, Arizona. Pages 166-174 in R.R. Johnson and D.A. Jones, technical coordinators. Importance, preservation, and management of riparian habitat: A symposium. General Technical Report RM43. U.S. Forest Service, Rocky Mountain Forest and Range Experiment Station, Fort Collins, Colorado.

Hickman, James C. (ed.). 1993. The Jepson manual. Berkeley, CA: University of California Press.

Hosmer, D.W. and Lemeshow, S. 2000. Applied logistic regression. Wiley. New York.

Huey, R.B., E.R. Pianka, and T.W. Schoener (eds.). 1983. Lizard ecology: Studies of a model organism. Harvard University Press. Cambridge, Massachusetts.

Hurlbert, Stuart H. 1984. Pseudoreplication and the design of ecological field experiments. Ecological Monographs. Vol 54, No. 2: 187-211.

Jones, K. Bruce. 1981. Effects of grazing on lizard abundance and diversity in western Arizona. The Southwestern Naturalist. Vol. 26 No. 2: 107-115.

Kauffman, J.B. and W.C. Krueger. 1984. Livestock impacts on riparian ecosystems and streamside management implications: A review. Journal of Range Management. Vol. 37:430-437.

Keller, C.R. and K.P. Burnham. 1982. Riparian fencing, grazing, and trout habitat preference on Summit Creek, Idaho. North American Journal of Fisheries Management. Vol. 2: 53-59.

Kelt, D.A. 1988. Dipodomys heermanni. Mammalian Species. No. 323:1-7.

Kjoss, Victoria A. and John A. Litvaitis. 2001. Comparison of 2 methods to sample snake communities in early successional habitats. Wildlife Society Bulletin. Vol. 29 No. 1: 153-157.

Minitab 16.1.1 Statistical Software. 2010. [Computer software]. State College, PA: Minitab, Inc.

Montanucci, Richard R. 1965. Observations on the San Joaquin leopard lizard, Crotaphytus wislizenii silus Stejneger. Herpetologica. Vol 21, No.4: 270-283.

Montanucci, Richard R. 1968. Notes on the distribution and ecology of some lizards in the San Joaquin Valley, California. Herpetologica. Vol. 24, No. 4: 316-320. 
Morrison, Michael L., William M. Block, M. Dale Strickland, William L. Kendall. 2001. Wildlife study designs. Pp. 102-104. Springer-Verlag, New York.

Pearson, Dean E. and Leonard F. Ruggiero. 2003. Transect versus grid trapping arrangements for sampling small-mammal communities. Wildlife Society Bulletin. Vol. 31, No. 2 pp. 454-459.

Platts, W.S. 1981. Influence of forest and rangeland management on anadromous fish habitat in Western North America, No. 7. Effects of livestock grazing. General Technical Report PNW-124. U.S. Forest Service, Pacific Northwest Forest and Range Experiment Station, Portland, Oregon.

Reynolds, T.D. and C.H. Trost. 1980. The response of native vertebrate populations to crested wheatgrass planting and grazing by sheep. Journal of Range

Management. Vol. 3:122-125.

Rummel, R.S. 1951. Some effects of livestock grazing on ponderosa pine forest and range in central Washington. Ecology. Vol. 32:594-607.

SAS 9.2. 2002-2008. [Computer software]. Cary, NC: SAS institute, Inc.

Savage, Jay M. 1960. Evolution of a peninsular herpetofauna. Systematic Zoology. Vol 9, Issue 3-4: 184-212.

Seigel, Richard A. 1993. Summary: future research on snakes, or how to combat "lizard envy". Pages 395-402 in Seigel, Richard A. and Joseph T. Collins. Snakes Ecology and Behavior. Blackburn Press. New Jersey.

Stebbins, Robert C. 2003. Western Reptiles and Amphibians 3rd edition. Houghton Mifflin Company, Boston and New York.

Szaro, R.C., S.C. Belfit, J.K. Aitkin, and J.N. Rinne. 1985. Impact of grazing on a riparian garter snake. Pages 359-363 in R.R. Johnson, C.D. Ziebell, D.R. Patton, P.F. Folliot and F. Hamre, technical coordinators, Riparian ecosystems and their management: Reconciling conflicting uses. General Technical Repot RM-120. U.S. Forest Service, Rocky Mountain Forest and Range Experiment Station, Fort Collins, Colorado.

U.S. General Accounting Office. 1988. Rangeland management: More emphasis needed on declining and overstocked grazing allotments. GAO/RCED-88-80. U.S. General Accounting Office, Washington, D.C.

Tinkle, Donald W. 1967. The life and demography of the side-blotched lizard, Uta stansburiana. Miscellaneous Publications Museum of Zoology, University of Michigan. No. 132. 
Van Velson, R. 1979. Effects of livestock grazing upon rainbow trout in Otter Creek, Nebraska. Pages 53-55 in O.B. Cope, ed. Proceedings of the forum - Grazing and riparian/stream ecosystems. Trout Unlimited, Denver, Colorado.

Verts, B.J. and L.N. Carraway. 1998. Land mammals of Oregon. University of California Press, Berkeley.

Webster, W.D. and J.K. Jones Jr. 1982. Reithrodontomys megalotis. Mammalian Species. 167:1-5.

White, G.C., K.P. Burnham, D.L. Otis, and D.R. Anderson. 1978. User's manual for program CAPTURE, Utah State Univ. Press, Logan, Utah. 


\section{Appendix A Tables}

\begin{tabular}{|c|c|c|c|}
\hline Site & Array & Easting & Northing \\
\hline \multirow[t]{5}{*}{ Grazed1 } & A & 230712 & 3897677 \\
\hline & B & 230730 & 3897582 \\
\hline & $\mathrm{C}$ & 230622 & 3897565 \\
\hline & $\mathrm{D}$ & 230612 & 3897674 \\
\hline & $\mathrm{E}$ & 230668 & 3897621 \\
\hline \multirow[t]{5}{*}{ Ungrazed1 } & $A$ & 230983 & 3897499 \\
\hline & B & 230985 & 3897394 \\
\hline & $\mathrm{C}$ & 230890 & 3897377 \\
\hline & $\mathrm{D}$ & 230876 & 3897492 \\
\hline & $\mathrm{E}$ & 230933 & 3897443 \\
\hline \multirow[t]{5}{*}{ Grazed2 } & $A$ & 229679 & 3896068 \\
\hline & B & 229723 & 3895971 \\
\hline & $\mathrm{C}$ & 229628 & 3895923 \\
\hline & $\mathrm{D}$ & 229581 & 3896024 \\
\hline & $\mathrm{E}$ & 229649 & 3895992 \\
\hline \multirow[t]{5}{*}{ Ungrazed2 } & $A$ & 229936 & 3895834 \\
\hline & B & 230042 & 3895884 \\
\hline & $\mathrm{C}$ & 229976 & 3895973 \\
\hline & $\mathrm{D}$ & 229891 & 3895920 \\
\hline & $\mathrm{E}$ & 229965 & 3895903 \\
\hline
\end{tabular}

Table 1. UTM coordinates (Zone 11S) for live trapping arrays used to sample reptiles. 


\begin{tabular}{ccc}
\hline Session & Fall 2009 & Spring 2010 \\
\hline \hline 1 & $10 / 16 / 2009-10 / 18 / 2009$ & $4 / 01 / 2010-4 / 03 / 2010$ \\
2 & $10 / 22 / 2009-10 / 25 / 2009$ & $4 / 06 / 2010-4 / 07 / 2010$ \\
3 & $10 / 29 / 2009-11 / 01 / 2009$ & $4 / 14 / 2010-4 / 17 / 2010$ \\
4 & $11 / 05 / 2009-11 / 08 / 2009$ & $4 / 24 / 2010-4 / 25 / 2010$ \\
5 & $11 / 11 / 2009-11 / 12 / 2009$ & $5 / 04 / 2010-5 / 08 / 2010$ \\
6 & N/A & $5 / 12 / 2010-5 / 15 / 2010$ \\
7 & N/A & $5 / 26 / 2010-5 / 29 / 2010$ \\
\hline N/A= Not sampled & & \\
\hline
\end{tabular}

Table 2. Dates in which reptile trapping occurred during fall 2009 and spring 2010. 


\begin{tabular}{l|cc|cc|c|c|c}
\hline & \multicolumn{3}{|c|}{ Live Trapping } & \multicolumn{2}{c}{ Visual Encounter Surveys } \\
\hline & $\begin{array}{c}\text { Common side } \\
\text { blotched } \\
\text { lizard }\end{array}$ & \multicolumn{2}{c|}{$\begin{array}{c}\text { Gilbert's } \\
\text { skink }\end{array}$} & $\begin{array}{c}\text { Common } \\
\text { side- } \\
\text { blotched } \\
\text { lizard }\end{array}$ & $\begin{array}{c}\text { N. Pacific } \\
\text { Rattlesnake }\end{array}$ & $\begin{array}{c}\text { Gopher } \\
\text { Snake }\end{array}$ \\
\hline \multicolumn{1}{c|}{ Site } & Fall & Spring & Fall & Spring & \multicolumn{3}{|c}{ Fall 2009 } \\
\hline Grazed1 & 13 & 9 & NA & 3 & 0 & 0 & 0 \\
Ungrazed1 & 21 & 61 & NA & 0 & 46 & 1 & 1 \\
Grazed2 & NA & 2 & NA & 2 & NA & NA & NA \\
Ungrazed2 & NA & 0 & NA & 0 & NA & NA & NA \\
\hline
\end{tabular}

Table 3. Summary of total captures among live trapping arrays and visual encounter surveys for reptile species captured during fall 2009 and spring 2010. 


\begin{tabular}{|c|c|c|c|c|c|}
\hline & & Fall & 009 & Spring & 2010 \\
\hline Site & Array & Coverboard & Drift fence & Coverboard & Drift fence \\
\hline Grazed1 & A & 0 & 0 & 0 & 0 \\
\hline & B & 7 & 0 & 5 & 0 \\
\hline & $\mathrm{C}$ & 0 & 0 & 4 & 0 \\
\hline & D & 1 & 1 & 0 & 0 \\
\hline & E & 4 & 0 & 2 & 1 \\
\hline Grazed2 & A & & & 2 & 0 \\
\hline & B & & & 0 & 1 \\
\hline & $\mathrm{C}$ & & & 1 & 0 \\
\hline & D & & & 0 & 0 \\
\hline & E & & & 0 & 0 \\
\hline Ungrazed1 & A & 8 & 1 & 19 & 0 \\
\hline & B & 0 & 0 & 0 & 0 \\
\hline & $\mathrm{C}$ & 5 & 1 & 5 & 0 \\
\hline & D & 3 & 2 & 12 & 1 \\
\hline & E & 1 & 3 & 22 & 2 \\
\hline Ungrazed2 & A & & & 0 & 0 \\
\hline & B & & & 0 & 0 \\
\hline & $\mathrm{C}$ & & & 0 & 0 \\
\hline & D & & & 0 & 0 \\
\hline & E & & & 0 & 0 \\
\hline Total & & 29 & 8 & 72 & 5 \\
\hline
\end{tabular}

Table 4. Summary of total reptile captures for each individual array across coverboards and drift fences with live traps. This summary reflects reptiles captured during the spring 2010 field season. Grazed 2 and Ungrazed 2 were not sampled during spring 2010. 


\begin{tabular}{lccccc}
\hline Method & Effort & Cost & Captures & Data & Marking \\
\hline \hline $\begin{array}{l}\text { Drift fences with live } \\
\text { traps }\end{array}$ & High & High & Low & High & Yes \\
$\begin{array}{l}\text { Coverboards } \\
\text { Medium }\end{array}$ & Medium & High & Low & No \\
$\begin{array}{l}\text { Visual encounter } \\
\text { surveys }\end{array}$ & Low & Low & High & Low & No \\
\hline
\end{tabular}

Table 5. An analysis of some attributes associated with sampling for reptiles using drift fences with live traps, cover boards, and visual encounter surveys. 


\begin{tabular}{|c|c|c|c|}
\hline \multirow[t]{2}{*}{ Fall 2009} & \multicolumn{3}{|c|}{ Unique Captures } \\
\hline & Grazed1 & Ungrazed1 & Total \\
\hline Chaetodipus californicus & $5(0.01)$ & $19(.04)$ & 24 \\
\hline Dipodomys heermanni & $3(0.01)$ & $4(0.01)$ & 7 \\
\hline Perognathus inornatus & $2(0.004)$ & $3(0.01)$ & 5 \\
\hline Peromyscus maniculatus & $17(0.03)$ & $20(0.04)$ & 37 \\
\hline Reithrodontomys megalotus & $0(0)$ & $1(.002)$ & 1 \\
\hline Grand Total & $27(0.05)$ & $47(0.09)$ & 74 \\
\hline Observed Species Richness & 4 & 5 & \\
\hline Simpson's Diversity Index & 0.45 & 0.37 & \\
\hline Chao1 \pm SD & $4.00 \pm 0.27$ & $4.74 \pm 0.22$ & \\
\hline $\begin{array}{l}\text { Abundance based } \\
\text { estimate } \pm \mathrm{SD}\end{array}$ & $4.33 \pm 1.13$ & $5.10 \pm 0.75$ & \\
\hline Jackknife $1 \pm$ SD & $4.16 \pm 0.24$ & $5.18 \pm 0.46$ & \\
\hline Average Species Richness & 4.16 & 5.01 & \\
\hline
\end{tabular}

Table 6. Summary of small mammal captures, observed richness and estimated richness during Fall 2009. Trapping effort consisted of 500 trap-nights per site. 


\begin{tabular}{l|lccccc}
\hline \multicolumn{1}{c|}{ Species } & \multicolumn{1}{c}{ Site } & $\begin{array}{c}\text { Unique } \\
\text { Captures }\end{array}$ & $\begin{array}{c}\text { Estimated } \\
(\mathbf{n})\end{array}$ & $\begin{array}{c}\mathbf{9 5 \%} \\
\text { CI }\end{array}$ & Model & $\begin{array}{c}\text { Capture } \\
\text { Probability }\end{array}$ \\
\hline \hline $\begin{array}{l}\text { Chaetodipus } \\
\text { californicus }\end{array}$ & Grazed1 & 5 & 5 & $5-11$ & $\mathrm{M}(0)$ & 0.356 \\
\hline $\begin{array}{l}\text { Dipodomys } \\
\text { heermanni }\end{array}$ & Ungrazed1 & 19 & 33 & $24-69$ & $\mathrm{M}(\mathrm{th})^{*}$ & 0.450 \\
\hline $\begin{array}{l}\text { Perognathus } \\
\text { inornatus }\end{array}$ & Grazed1 & 3 & 4 & $4-13$ & $\mathrm{M}(\mathrm{th})^{*}$ & 0.750 \\
\hline $\begin{array}{l}\text { Peromyscus } \\
\text { maniculatus }\end{array}$ & Grazed1 & 2 & 2 & $2-2$ & $\mathrm{M}(0)$ & 0.400 \\
\hline $\begin{array}{l}\text { Reithrodontomys } \\
\text { megalotus }\end{array}$ & Gngrazed1 & 3 & 3 & $3-3$ & $\mathrm{M}(0)$ & 0.333 \\
\hline
\end{tabular}

*Detection probability was the average capture probability across trap-nights.

Table 7. Summary of observed unique captures and population estimates calculated derived from mark-release-recapture data and capture probabilities (CAPTURE) for five small mammal species on a grazed and ungrazed site during fall 2009. 


\begin{tabular}{|c|c|c|c|c|}
\hline \multicolumn{5}{|c|}{ Basal Cover } \\
\hline Site & Bare Soil & Forb & Grass & Litter \\
\hline Grazed1 & $34.00 \pm 7.90$ & $22.67 \pm 6.44$ & $28.44 \pm 7.60$ & $14.89 \pm 5.08$ \\
\hline Grazed 2 & $13.20 \pm 3.35$ & $54.60 \pm 6.37$ & $11.80 \pm 2.61$ & $20.40 \pm 4.88$ \\
\hline Ungrazed1 & $30.40 \pm 6.88$ & $22.60 \pm 3.91$ & $31.40 \pm 6.68$ & $15.60 \pm 2.53$ \\
\hline Ungrazed2 & $10.20 \pm 1.80$ & $52.60 \pm 4.83$ & $16.80 \pm 5.38$ & $20.60 \pm 4.03$ \\
\hline \multicolumn{5}{|c|}{ Canopy Cover } \\
\hline Site & Forb & Grass & Shrub & Total \\
\hline Grazed1 & $60.67 \pm 5.56$ & $65.33 \pm 6.63$ & 0.00 & $92.89 \pm 3.00$ \\
\hline Grazed2 & $69.60 \pm 3.98$ & $83.80 \pm 2.61$ & 0.00 & $96.20 \pm 0.81$ \\
\hline Ungrazed1 & $37.40 \pm 6.01$ & $64.20 \pm 8.57$ & $2.40 \pm 1.29$ & $85.80 \pm 4.26$ \\
\hline Ungrazed2 & $70.60 \pm 3.88$ & $65.00 \pm 5.11$ & 0.00 & $95.40 \pm 1.23$ \\
\hline
\end{tabular}

Table 8. Average \pm SE basal and canopy coverage estimated from point intercept data. 


\begin{tabular}{|c|c|c|c|c|c|c|}
\hline \multicolumn{2}{|c|}{$\begin{array}{l}\text { Entrance } \\
\text { Diameter }\end{array}$} & Grazed1 & Ungrazed1 & Grazed2 & Ungrazed 2 & Total \\
\hline \multirow[t]{3}{*}{$<2 \mathrm{~cm}$} & Observed & 1 & 1 & 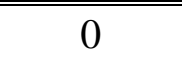 & 3 & 5 \\
\hline & Expected & 1.84 & 2.3 & 0.23 & 0.63 & \\
\hline & $\chi^{2}$ & 0.383 & 0.734 & 0.23 & 8.869 & \\
\hline \multirow[t]{3}{*}{$2-4 \mathrm{~cm}$} & Observed & 11 & 14 & 0 & 6 & 31 \\
\hline & Expected & 11.4 & 14.25 & 1.43 & 3.92 & \\
\hline & $\chi^{2}$ & 0.014 & 0.004 & 1.425 & 1.104 & \\
\hline \multirow[t]{3}{*}{$4-8 \mathrm{~cm}$} & Observed & 16 & 19 & 2 & 2 & 39 \\
\hline & Expected & 14.34 & 17.93 & 1.79 & 4.93 & \\
\hline & $\chi^{2}$ & 0.191 & 0.064 & 0.024 & 1.742 & \\
\hline \multirow[t]{3}{*}{$\geq 8 \mathrm{~cm}$} & Observed & 4 & 6 & 2 & 0 & 12 \\
\hline & Expected & 4.41 & 5.52 & 0.55 & 1.52 & \\
\hline & $\chi^{2}$ & 0.039 & 0.042 & 3.802 & 1.517 & \\
\hline
\end{tabular}

Table 9. Chi-square table for small mammal burrow entrance diameters. 


\begin{tabular}{|c|c|c|}
\hline Covariate & $\begin{array}{c}\text { Data } \\
\text { collected }\end{array}$ & Definition \\
\hline Grazed & Center & $\begin{array}{l}\text { A determination of whether the array occurs within a } \\
\text { grazed or ungrazed pasture. }\end{array}$ \\
\hline Aspect & Center & North or South facing. \\
\hline Shrubs & Center & $\begin{array}{l}\text { Determination of shrub presence within } 10 \mathrm{~m} \text { of the } \\
\text { center of an array (Yes or No) }\end{array}$ \\
\hline Slope & Quadrat & $\begin{array}{l}\text { Slope within each quadrat was recorded using a } \\
\text { clinometer }\end{array}$ \\
\hline Holes & Quadrat & $\begin{array}{l}\text { Number of burrows with entrance diameters }>2 \mathrm{~cm} \\
\text { within each quadrat }\end{array}$ \\
\hline Forb height & Quadrat & $\begin{array}{l}\text { The height }(\mathrm{cm}) \text { of a representative individual within } \\
\text { each quadrat }\end{array}$ \\
\hline Grass height & Quadrat & $\begin{array}{l}\text { The height }(\mathrm{cm}) \text { of a representative individual within } \\
\text { each quadrat }\end{array}$ \\
\hline $\begin{array}{l}\text { Bare soil } \\
\text { cover }\end{array}$ & Quadrat & $\begin{array}{l}\text { Visual percent cover estimation within each quadrat } \\
\text { using the methodology presented in Elzinga et al. } 1998\end{array}$ \\
\hline Grass cover & Quadrat & $\begin{array}{l}\text { Visual percent cover estimation within each quadrat } \\
\text { using the methodology presented in Elzinga et al. } 1998\end{array}$ \\
\hline Forb cover & Quadrat & $\begin{array}{l}\text { Visual percent cover estimation within each quadrat } \\
\text { using the methodology presented in Elzinga et al. } 1998\end{array}$ \\
\hline
\end{tabular}

Table 10. Summary of habitat covariates used to explain Uta stansburiana presence at array locations. 


\begin{tabular}{lccccccc}
\hline \multicolumn{1}{c}{ Variable } & Coeff. & SE & Odds ratio & OR 95\% CI & G & df $\begin{array}{c}\text { p (likelihood } \\
\text { ratio) }\end{array}$ \\
\hline \hline Grazed & -0.442 & 0.945 & 0.64 & $0.10-4.10$ & 0.220 & 1 & 0.639 \\
Aspect & 0.588 & 1.265 & 1.80 & $0.15-21.48$ & 0.229 & 1 & 0.632 \\
Slope & 0.077 & 0.110 & 1.08 & $0.87-1.34$ & 0.493 & 1 & 0.483 \\
Grass height & -0.095 & 0.054 & 0.91 & $0.82-1.01$ & 4.051 & 1 & 0.044 \\
Forb height & -0.068 & 0.099 & 0.93 & $0.77-1.13$ & 0.594 & 1 & 0.441 \\
Forb cover & -0.026 & 0.032 & 0.97 & $0.92-1.04$ & 0.719 & 1 & 0.396 \\
Grass cover & -0.063 & 0.037 & 0.94 & $0.87-1.01$ & 3.947 & 1 & 0.047 \\
Bare soil cover & 0.058 & 0.028 & 1.06 & $1.00-1.12$ & 5.279 & 1 & 0.022 \\
Holes & 0.932 & 0.538 & 2.54 & $0.88-7.29$ & 3.635 & 1 & 0.057 \\
Shrubs & Quasi complete separation of data points (questionable model fit) \\
\hline
\end{tabular}

Table 11. Results of univariate logistic regression analysis for individual covariates hypothesized to predict Uta stansburiana presence at an array. 


\begin{tabular}{l|ccc}
\hline & Bare soil cover & Grass cover & Holes \\
\hline \hline Grass cover & $\mathbf{- 0 . 6 5 5 / 0 . 0 0 2}$ & ---- & --- \\
Holes & $0.399 / 0.082$ & $-0.091 / 0.704$ & --- \\
Grass height & $\mathbf{- 0 . 6 6 5 / 0 . 0 0 1}$ & $\mathbf{0 . 7 2 3 / 0}$ & $-0.207 / 0.381$ \\
\hline \multicolumn{2}{l}{ Pearson correlation coefficient / p-value }
\end{tabular}

Pearson correlation coefficient / p-value

Table 12. Correlation matrix of covariates hypothesized to predict Uta stansburiana presence at arrays whose univariate analysis likelihood ratio p-value was $<0.25$. Pearson correlation coefficient / $p$-values in bold indicate pairs of covariates that were $>60 \%$ correlated. 


\begin{tabular}{lccccccc}
\hline \multicolumn{1}{c}{ Model } & K & $\mathbf{( - )} \mathbf{2} \log \mathbf{L}$ & AIC & AICc* & $\Delta$ AICc & $\begin{array}{c}\text { Model } \\
\text { likelihood }\end{array}$ & $w_{\mathbf{i}}$ \\
\hline \hline Bare soil cover & 3 & 20.619 & 26.619 & 28.12 & 0 & 1.00 & 0.54 \\
Holes & 3 & 22.263 & 28.263 & 29.76 & 1.64 & 0.44 & 0.24 \\
Bare soil cover + holes & 4 & 19.236 & 27.236 & 29.90 & 1.78 & 0.41 & 0.22 \\
\hline
\end{tabular}

$* \mathrm{n} / \mathrm{k}<40$

Table 13. Results of logistic regression analysis for all combinations of remaining covariates hypothesized to predict Uta stansburiana presence at arrays once nonsignificant and variables that were $>60 \%$ correlated were removed. 


\section{Appendix B Figures}

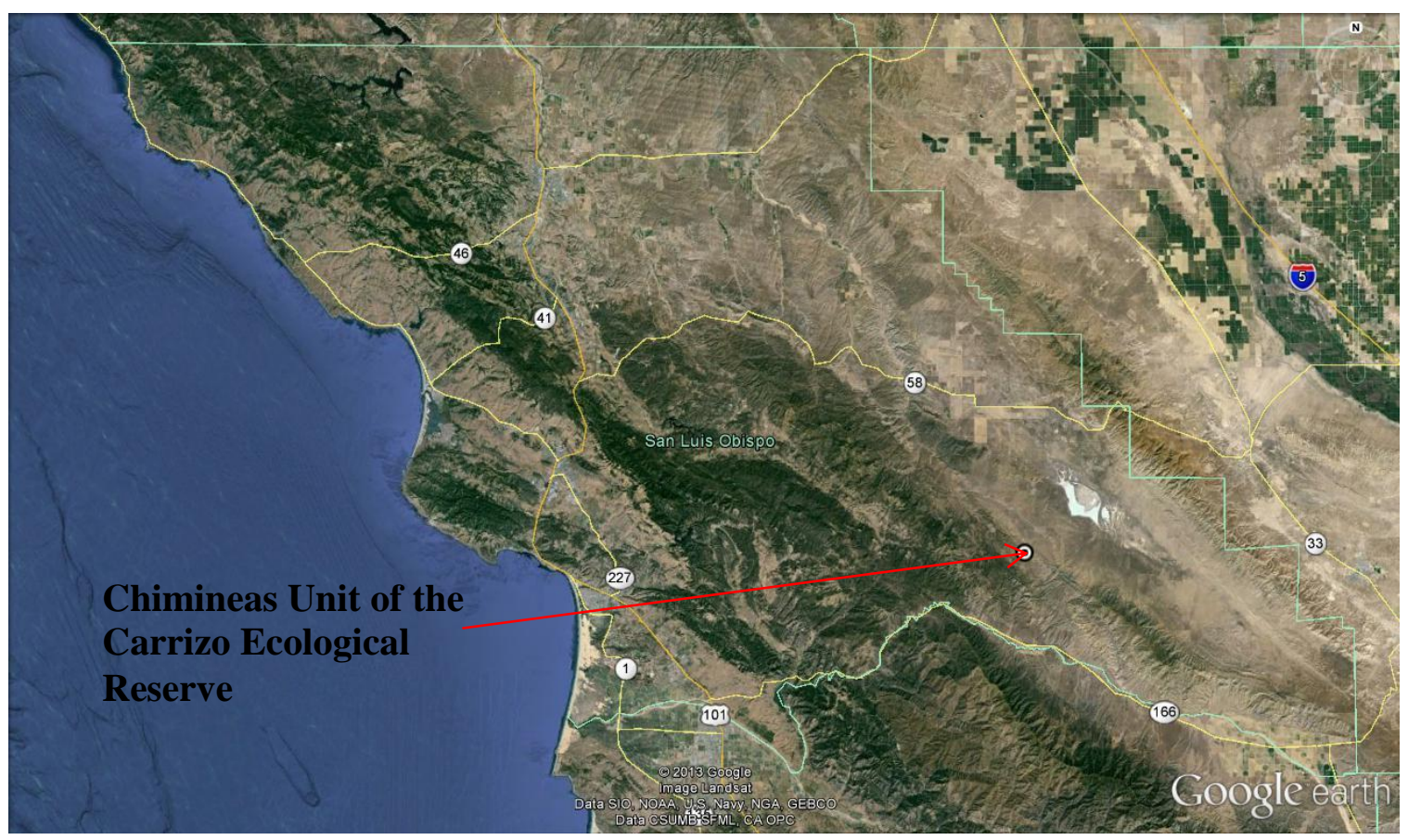

Figure 1. Map depicting San Luis Obispo County, California and the location of the Chimineas Unit of the California Department of Fish and Game Carrizo Ecological Reserve. Google Earth. 


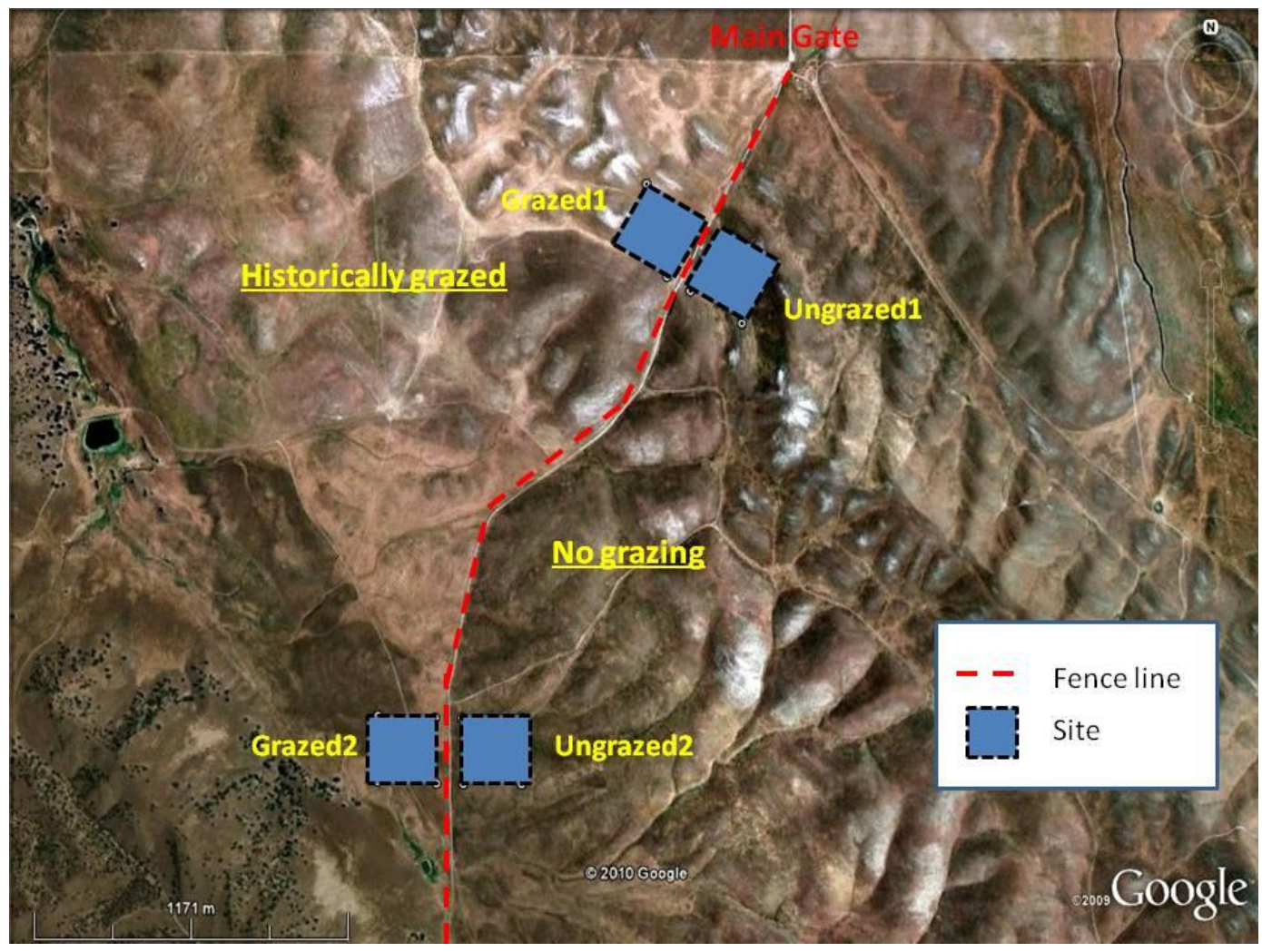

Figure 2. Map of the study area with locations of each matched pair of sites. Google Earth. 


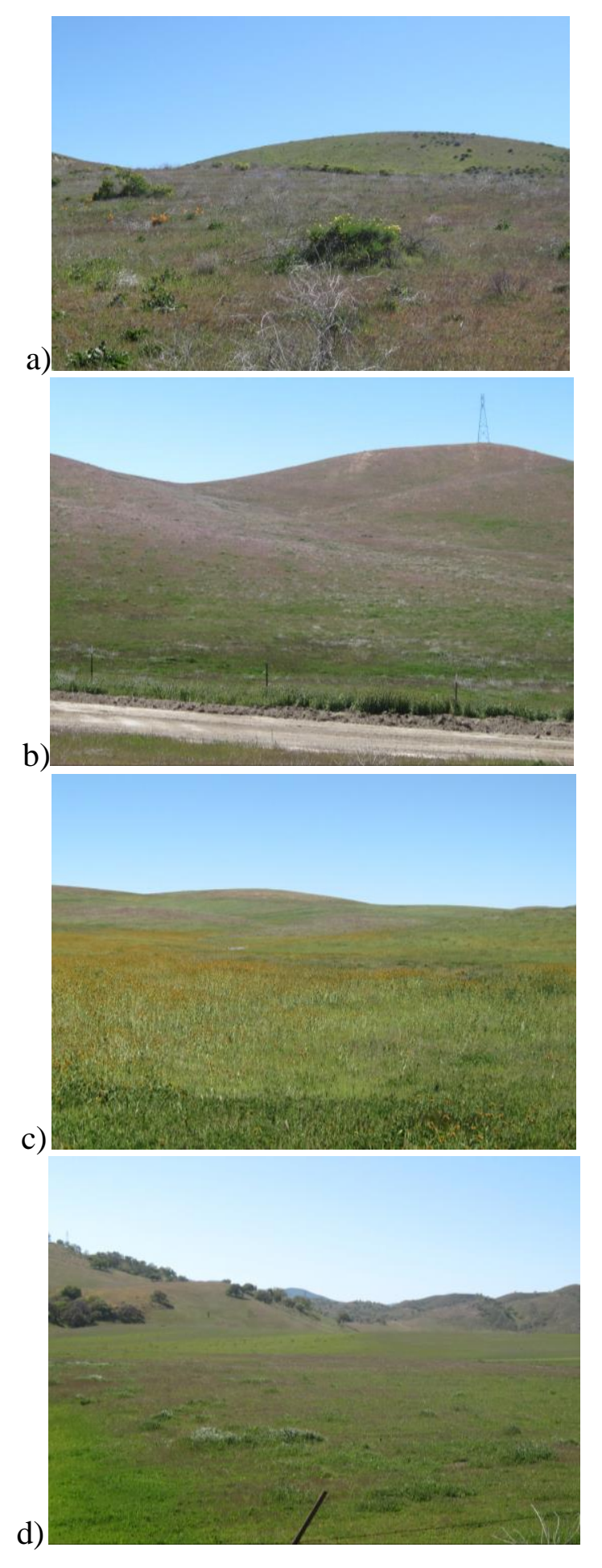

Figure 3. Photographs of each site representing the typical grassland habitat in this region. Photos were taken in May of 2010. a) Ungrazed1 facing east b) Grazed1 facing west c) Ungrazed2 facing east d) Grazed2 facing west. 


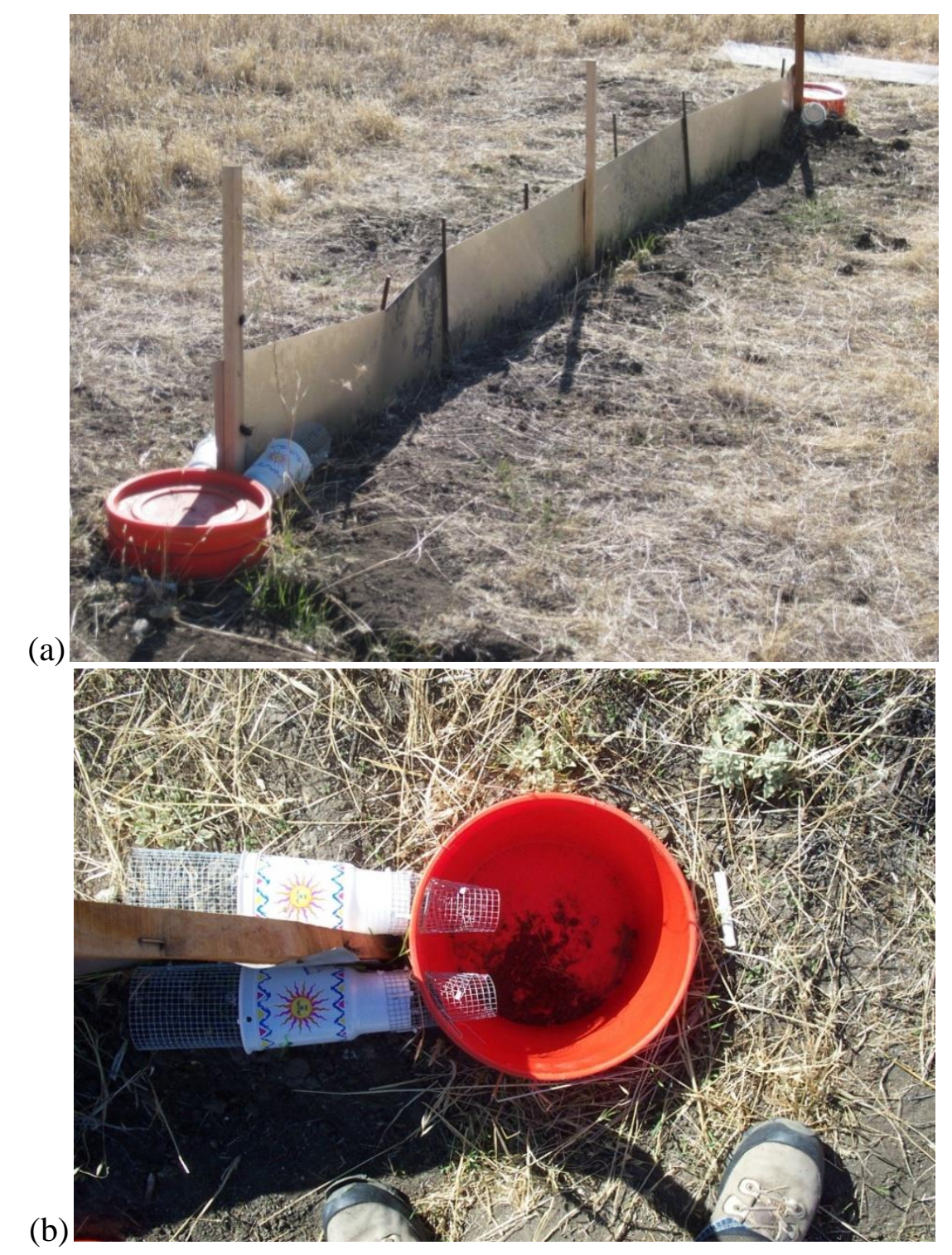

Figure 4. (a) A fully functional live trapping array with drift fence and coverboards. (b) Overview of a live trap at the end of a drift fence with two funnels leading into a five gallon bucket. 


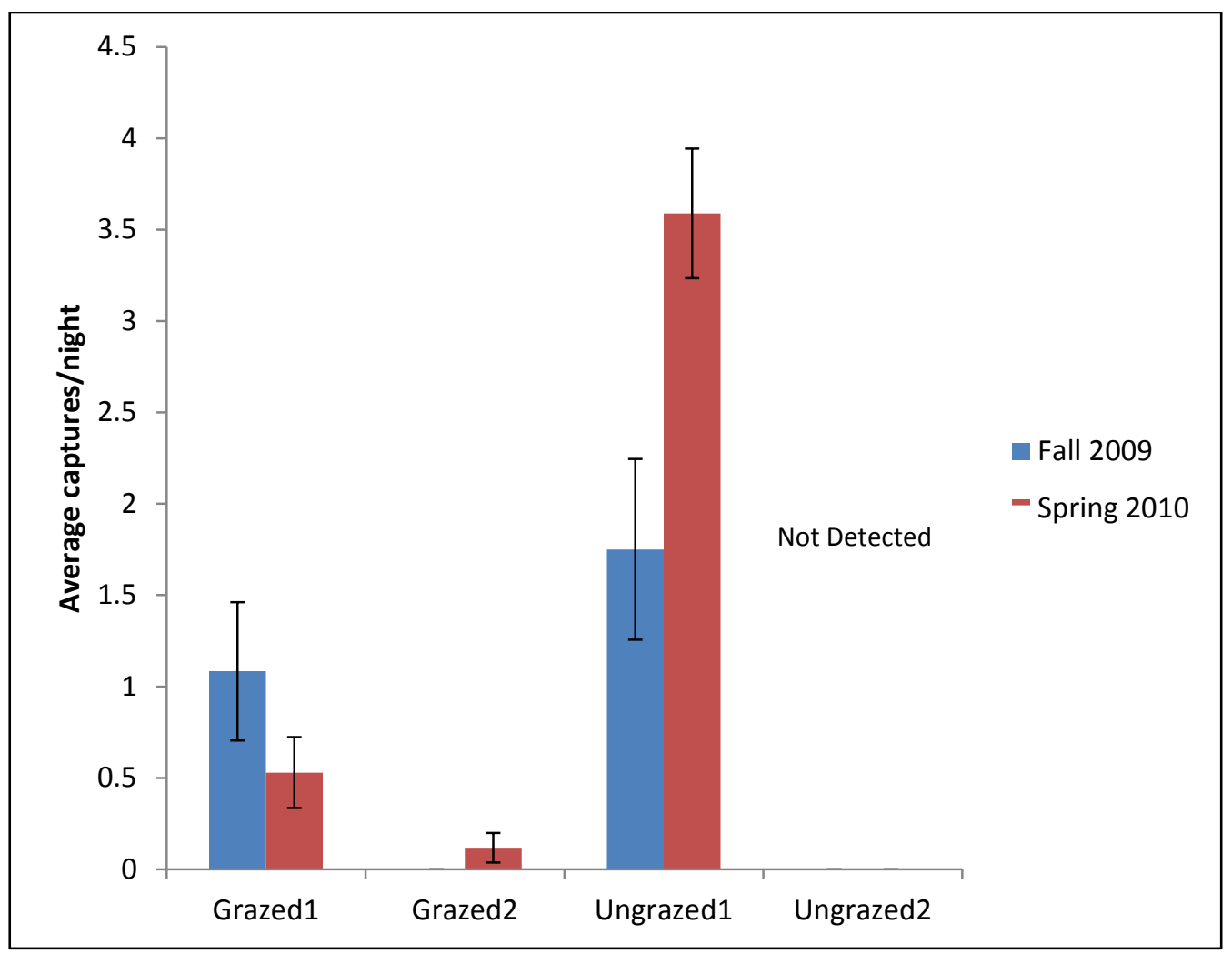

Figure 5. Average \pm SE Uta stansburiana captures/night during two sampling seasons on two grazed and two ungrazed sites. Sites Grazed 2 and Ungrazed 2 were not sampled during the fall. 


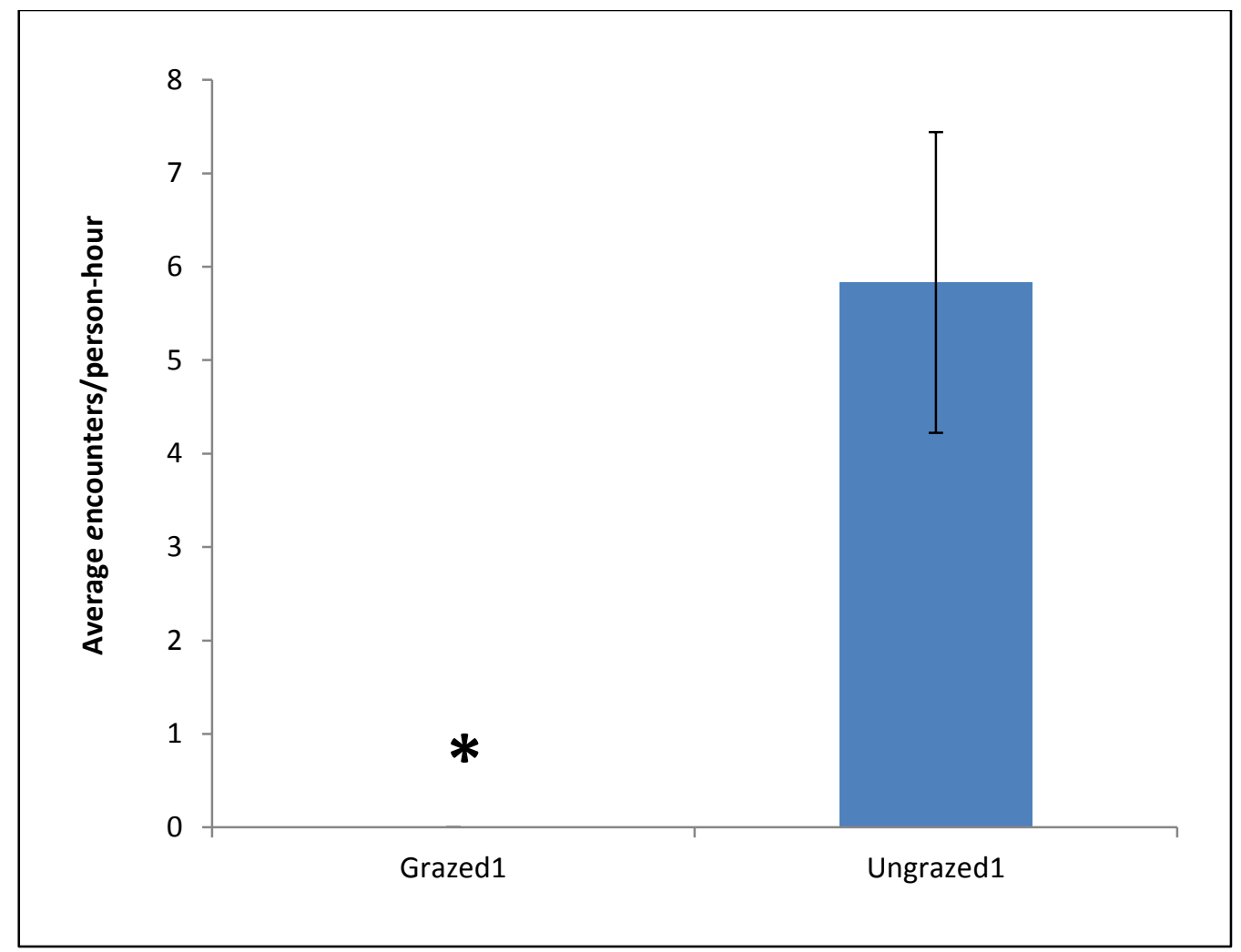

Figure 6. Average \pm SE Uta stansburiana encounters/person-hour during visual encounter surveys of the Fall 2009 pilot study. *Species not detected 


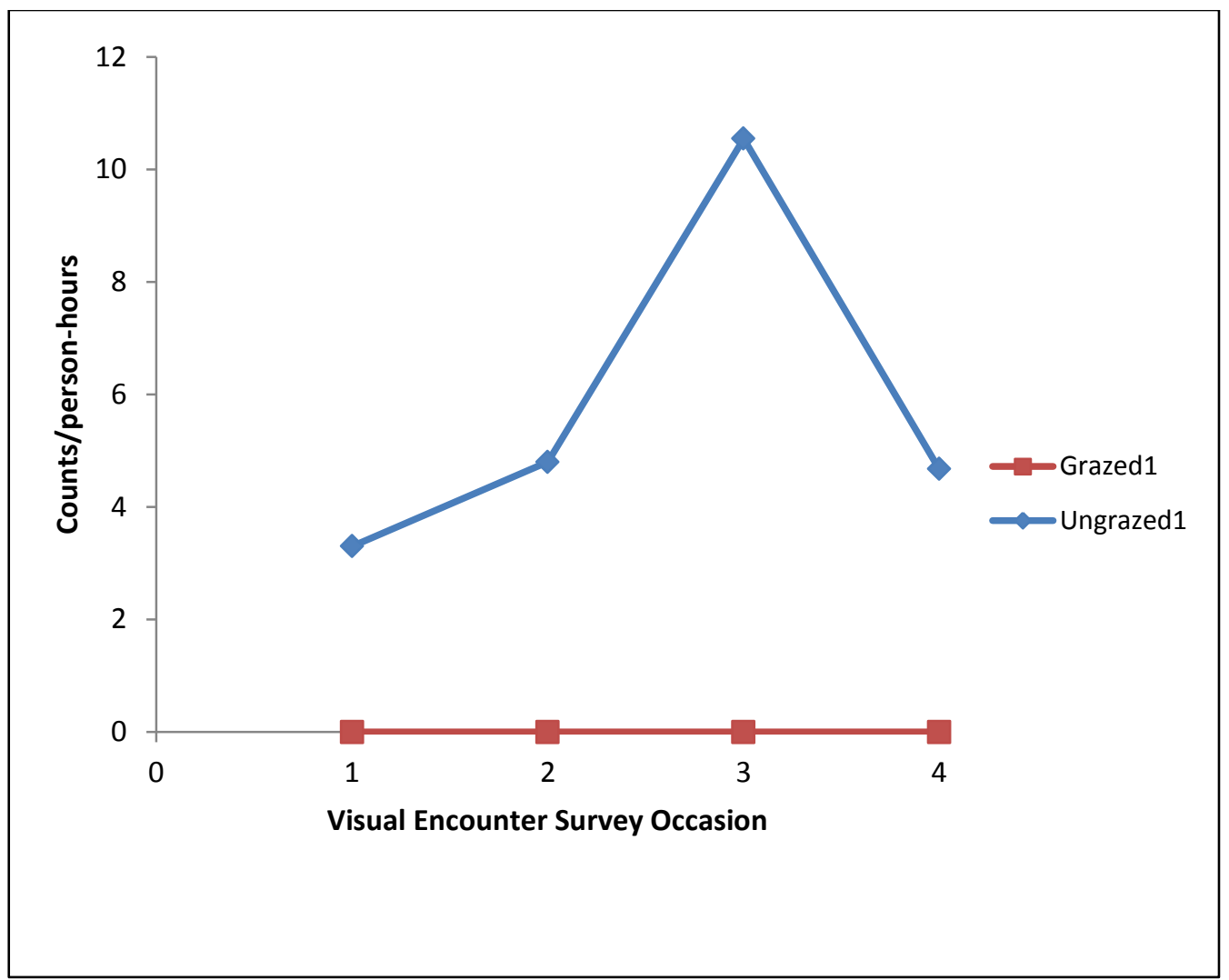

Figure 7. Uta stansburiana encounters/person-hour for four visual encounter survey occasions during the Fall 2009 pilot study. 


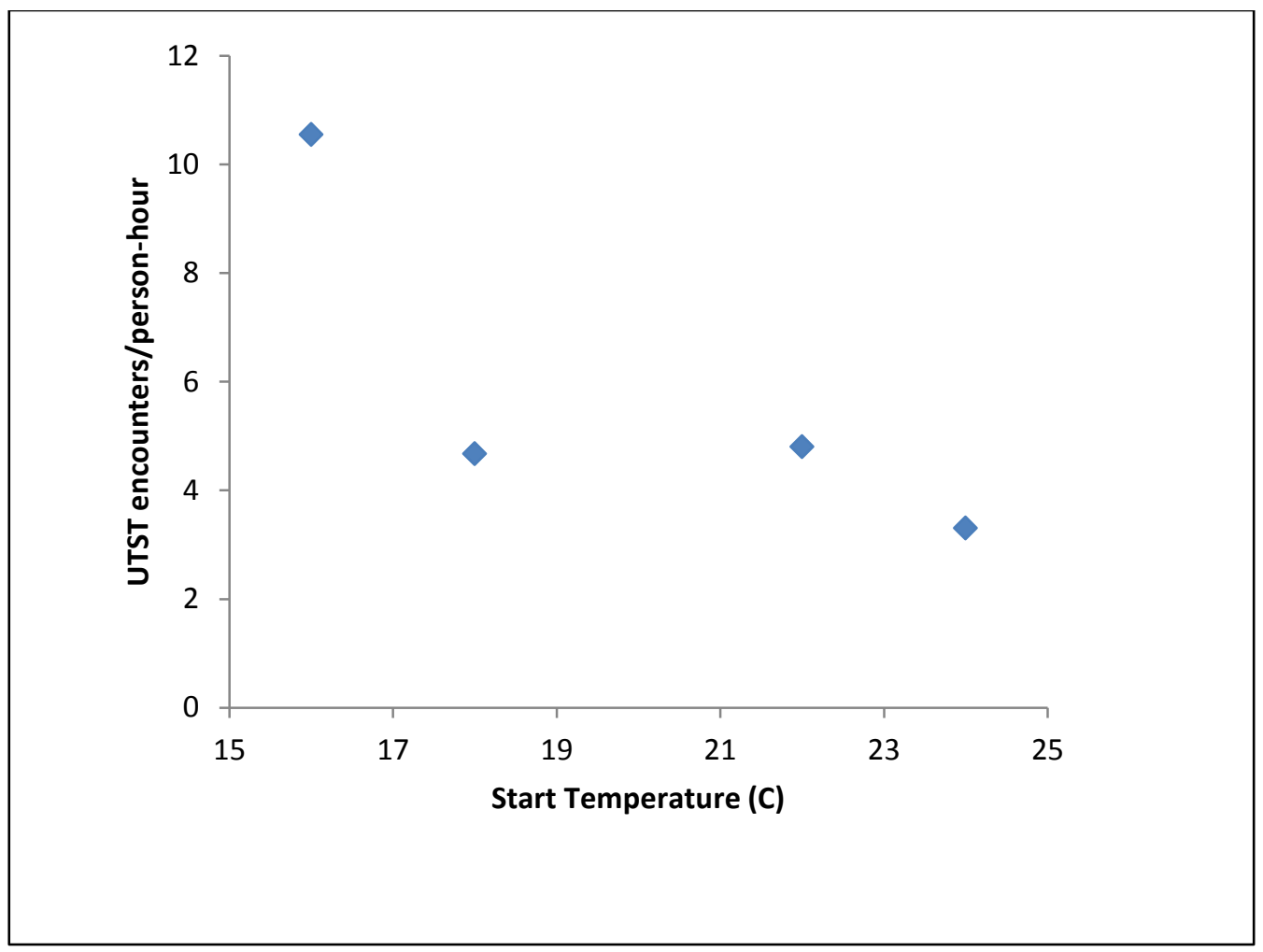

Figure 8. Starting temperature versus Uta encounter rate for 4 visual encounter survey occasions during fall 2009 on Ungrazed1. 


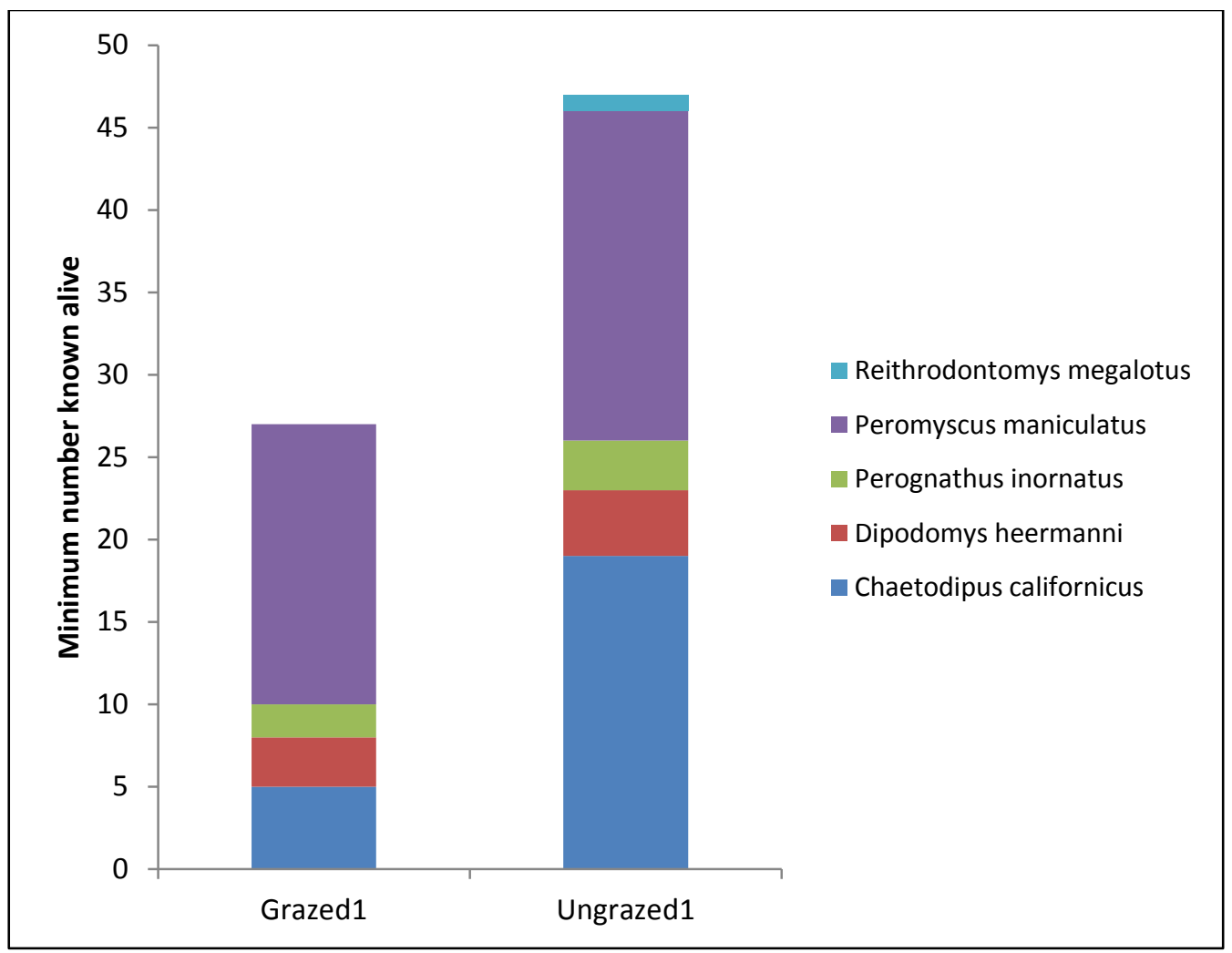

Figure 9. Relative frequency of the minimum number known alive for each small mammal species captured during 500 trap-nights per site. 


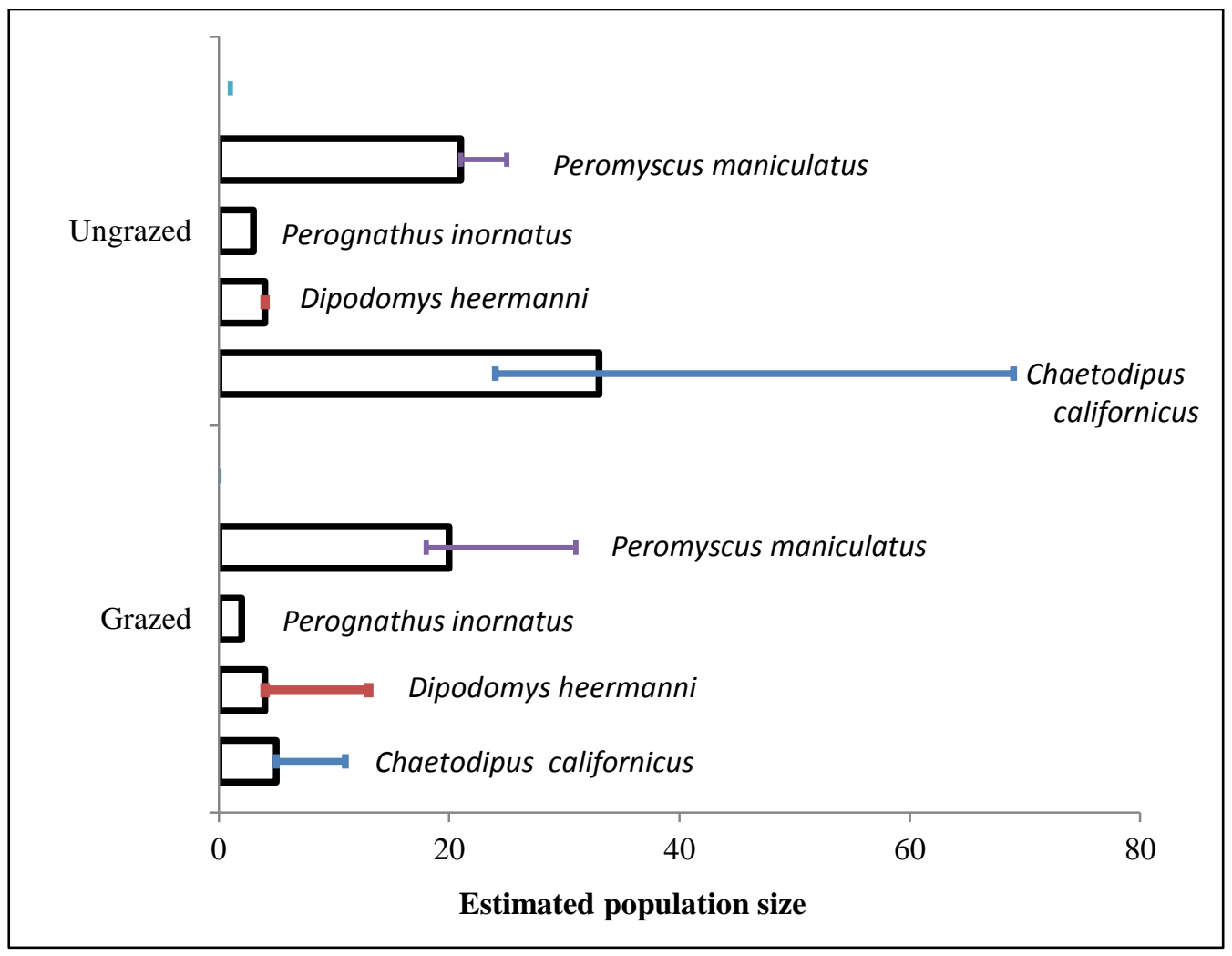

Figure 10. Capture probability based population estimates generated from markrelease-recapture data analyzed with program CAPTURE for four small mammal species on Grazed 1 and Ungrazed1. Error bars represent 95\% confidence intervals. These confidence intervals are non-symmetrical as most of the error is in estimating the portion of the population that was not captured. 


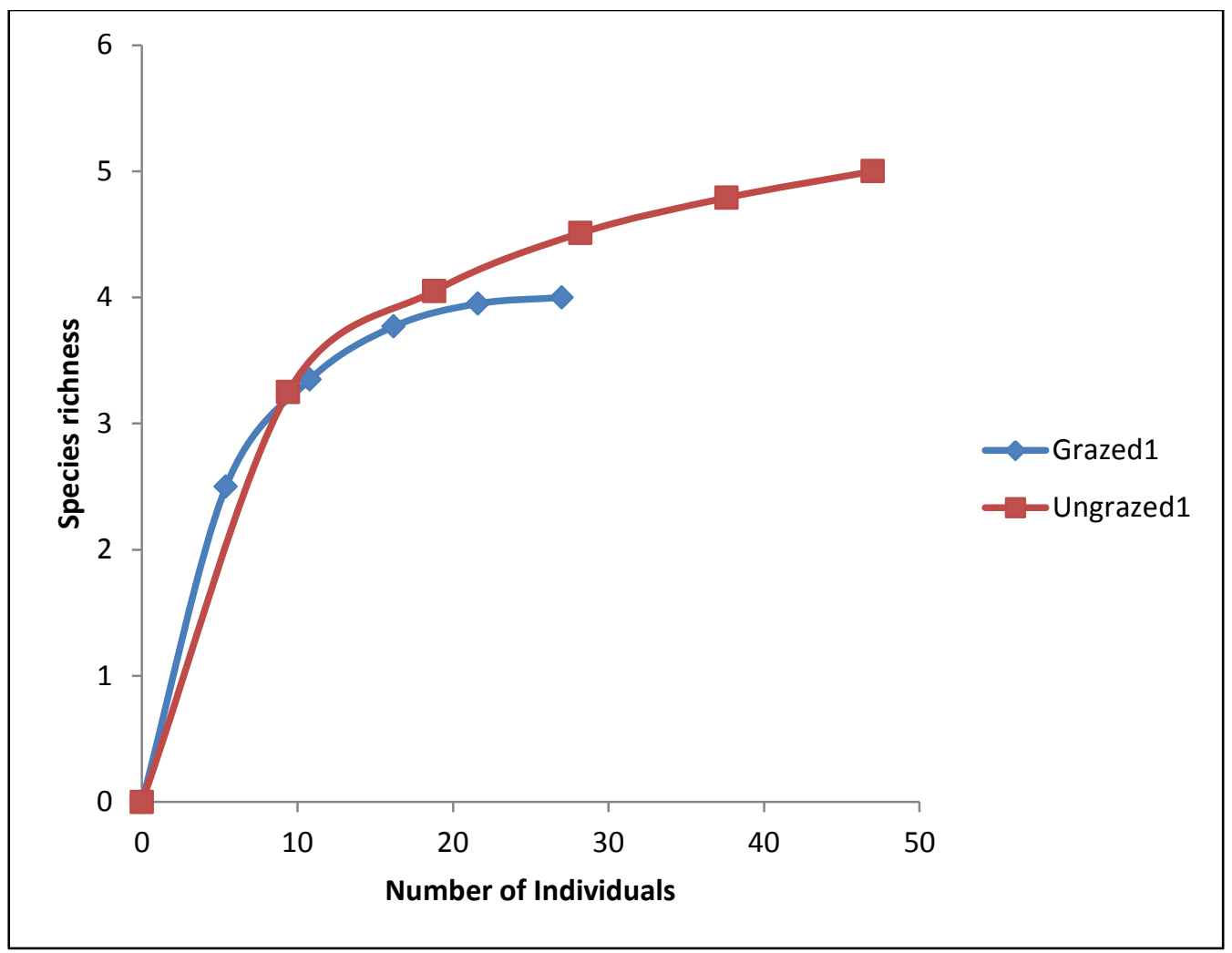

Figure 11. Small mammal species richness analysis using program EstimateS. Individual based Coleman rarefaction curve of the accumulated number of species as a function of the number of individuals captured. 


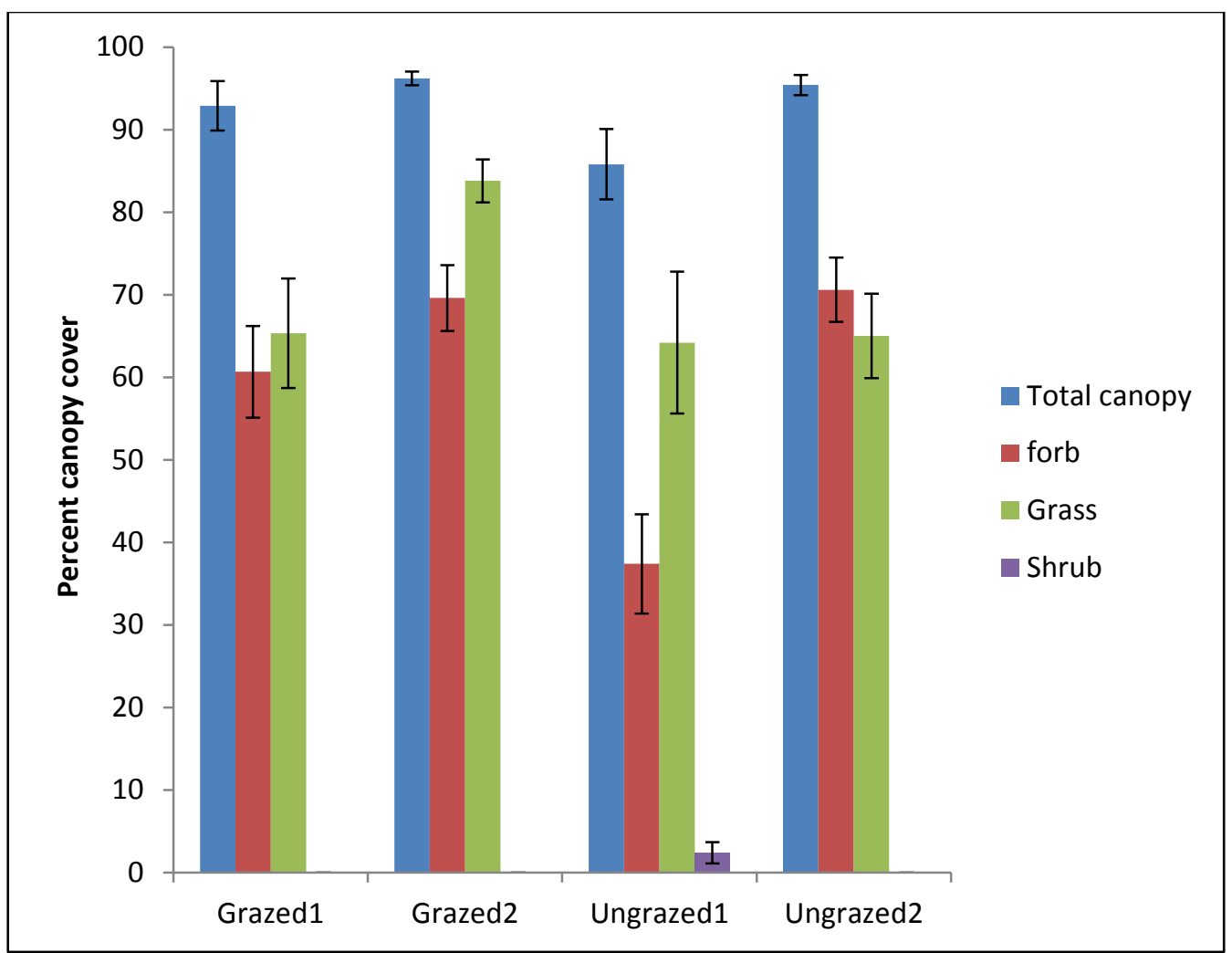

Figure 12. Average \pm SE canopy cover during spring 2010 estimated from point intercept data for forbs, grasses and shrubs. Shrubs were encountered only at Ungrazed1. 


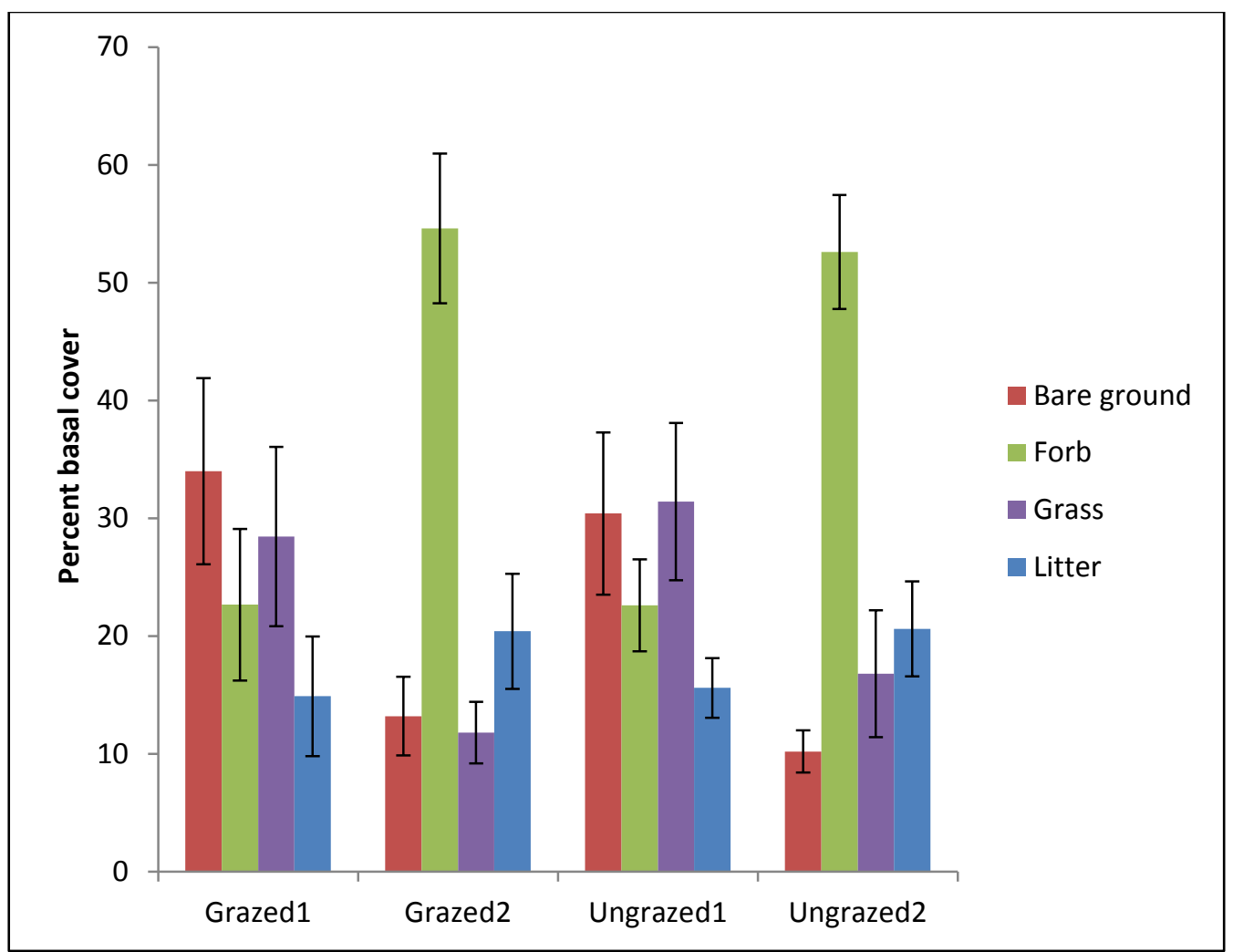

Figure 13. Average \pm SE basal cover during spring 2010 estimated from point intercept data for bare ground, forbs, grasses and litter. 


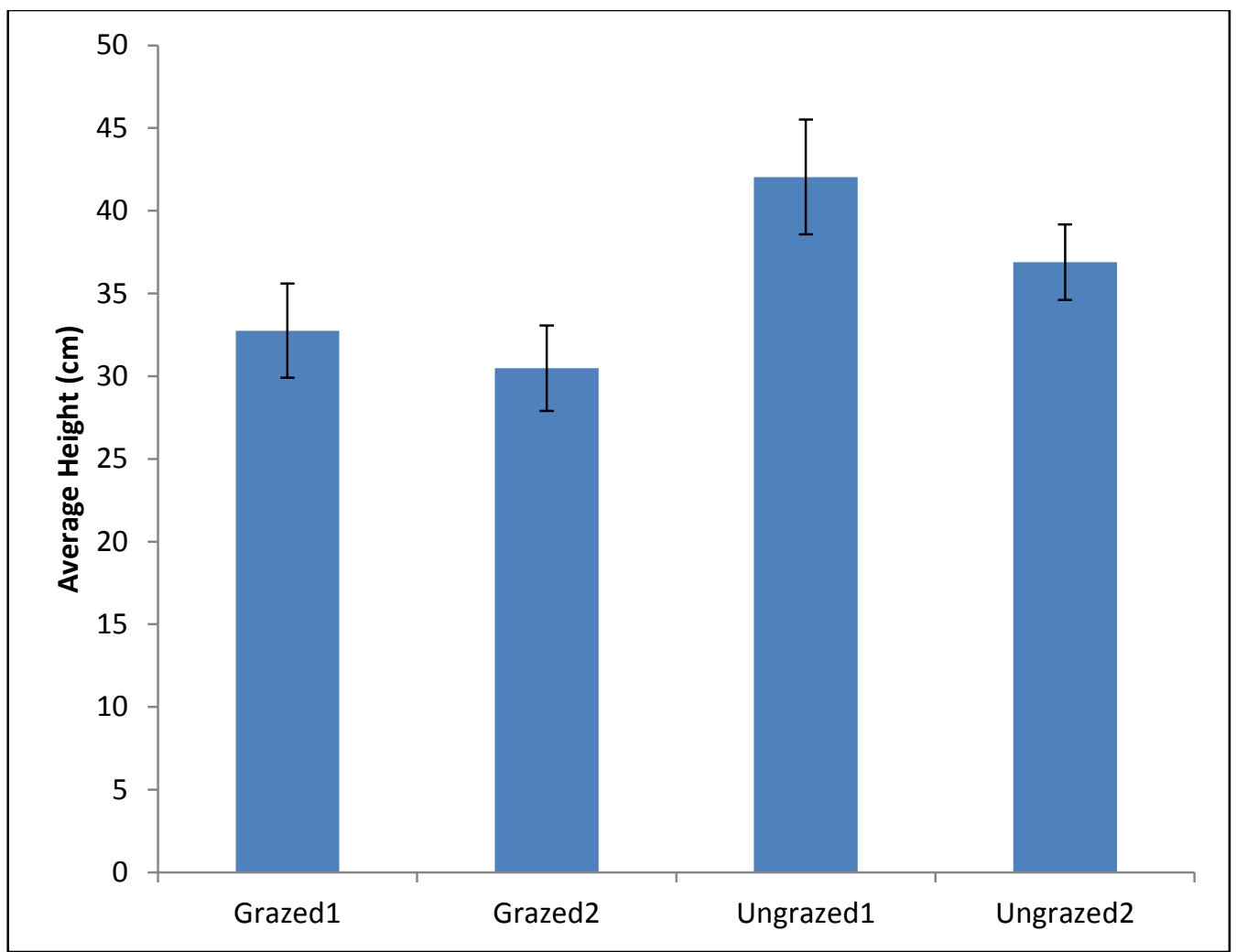

Figure 14. Average \pm SE canopy height during spring 2010 estimated from point intercept data on two grazed and two ungrazed sites. Average values for each site were calculated using the average canopy height of the sampling points within each transect. 


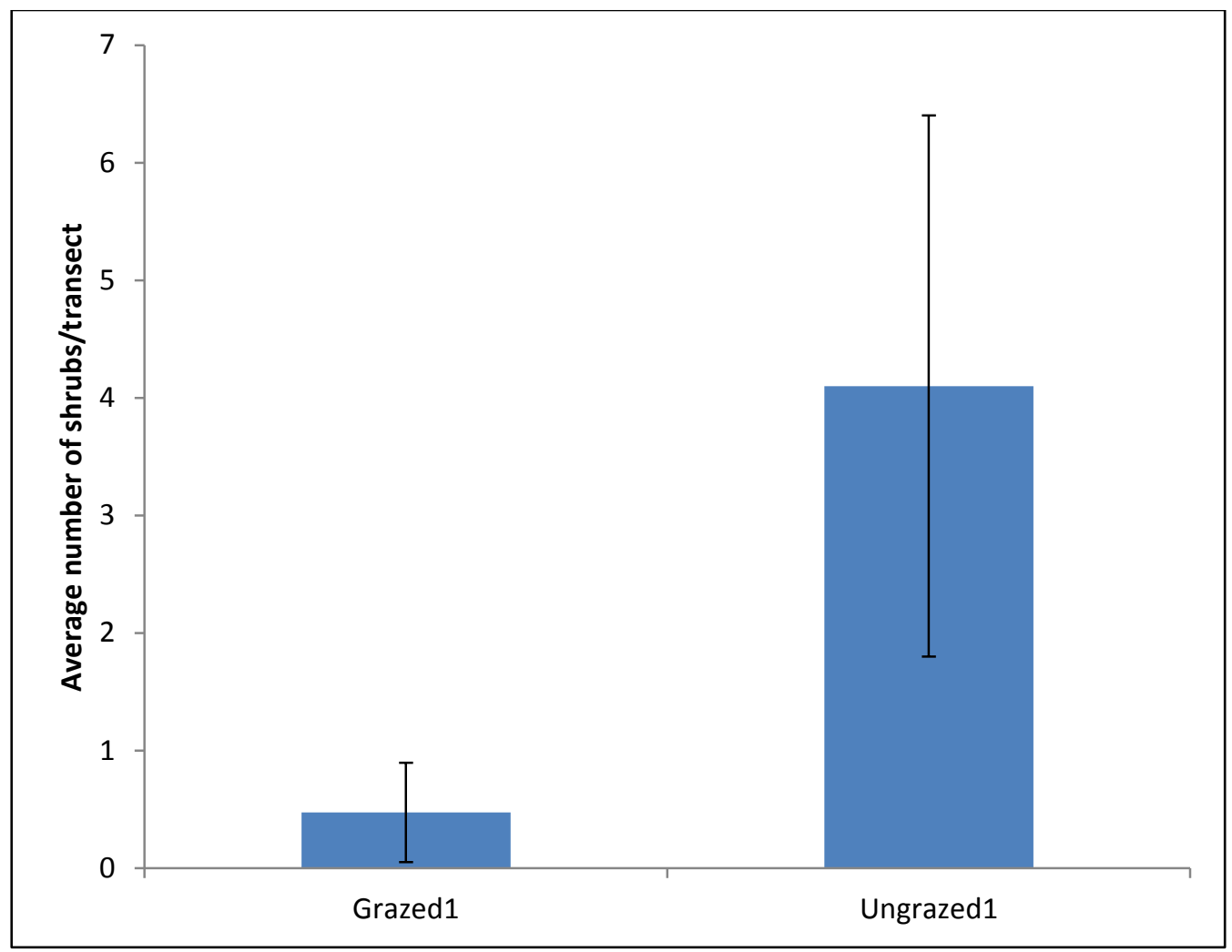

Figure 15. Average \pm SE number of shrubs/transect for Grazed1 and Ungrazed 1 during spring 2010. Shrubs were not encountered on Grazed2 and Ungrazed2. 


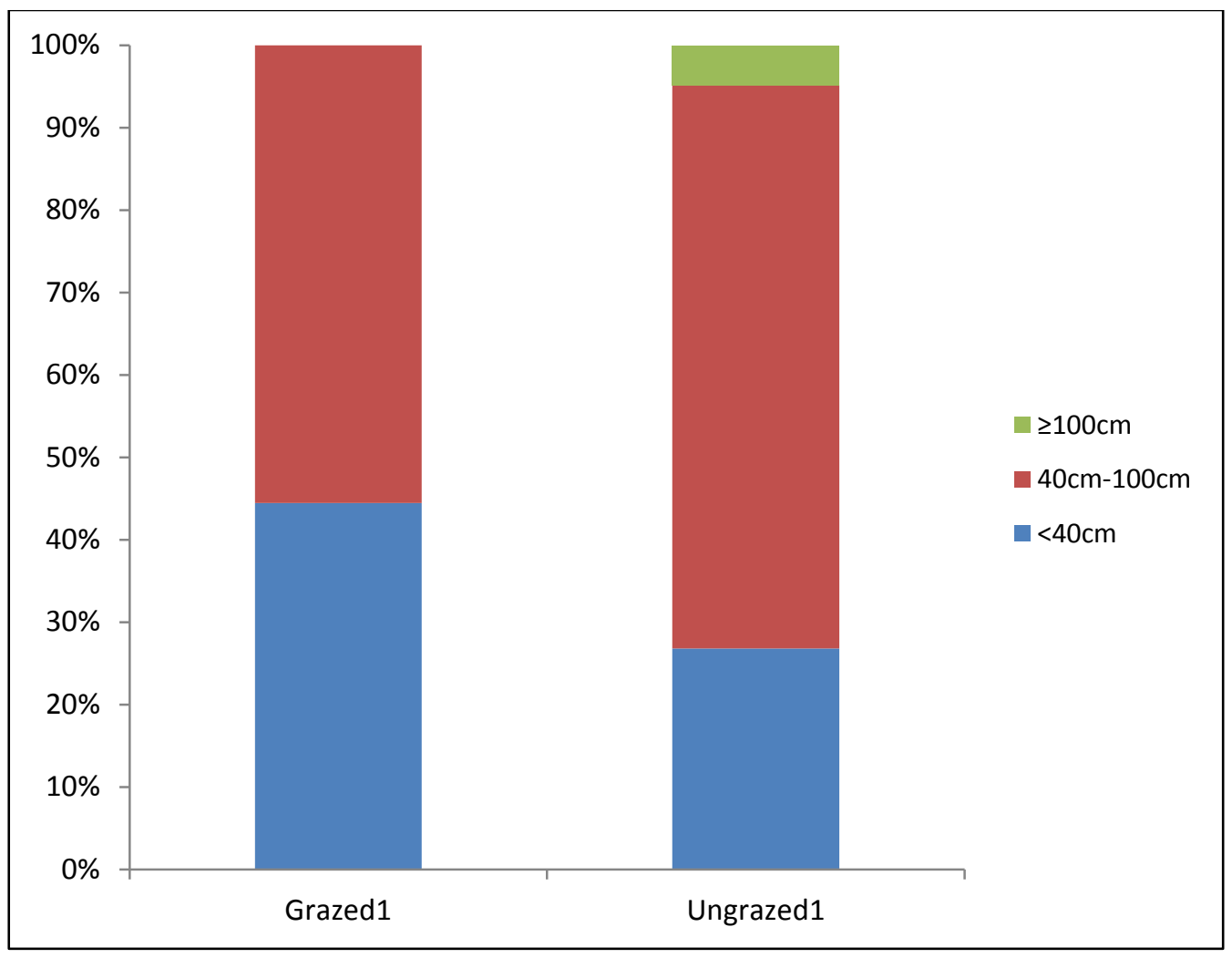

Figure 16. Distribution of shrub heights at Grazed1 and Ungrzed1 found on strip transects. 


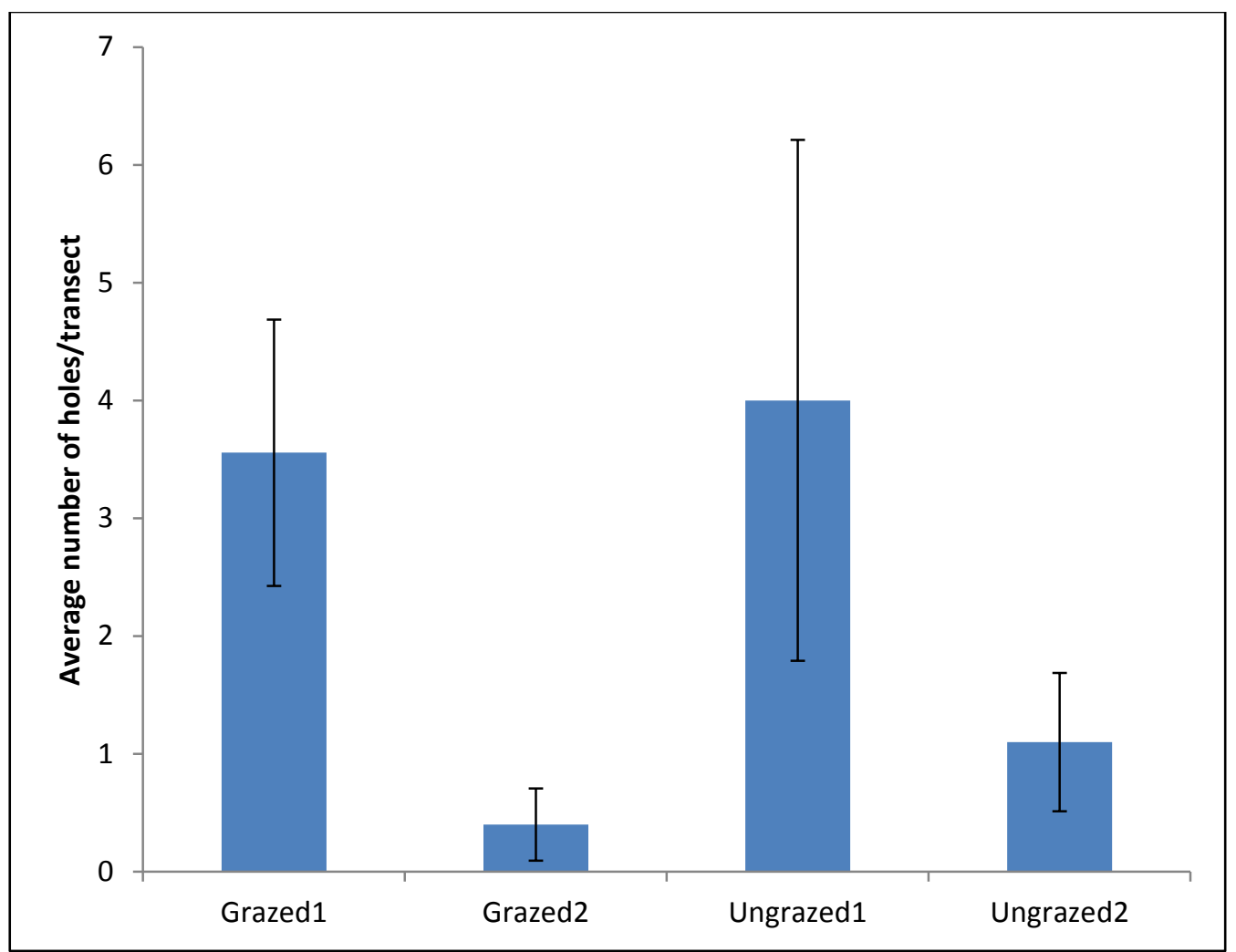

Figure 17. Average \pm SE number of holes/transect for two grazed and two ungrazed sites during spring 2010. 


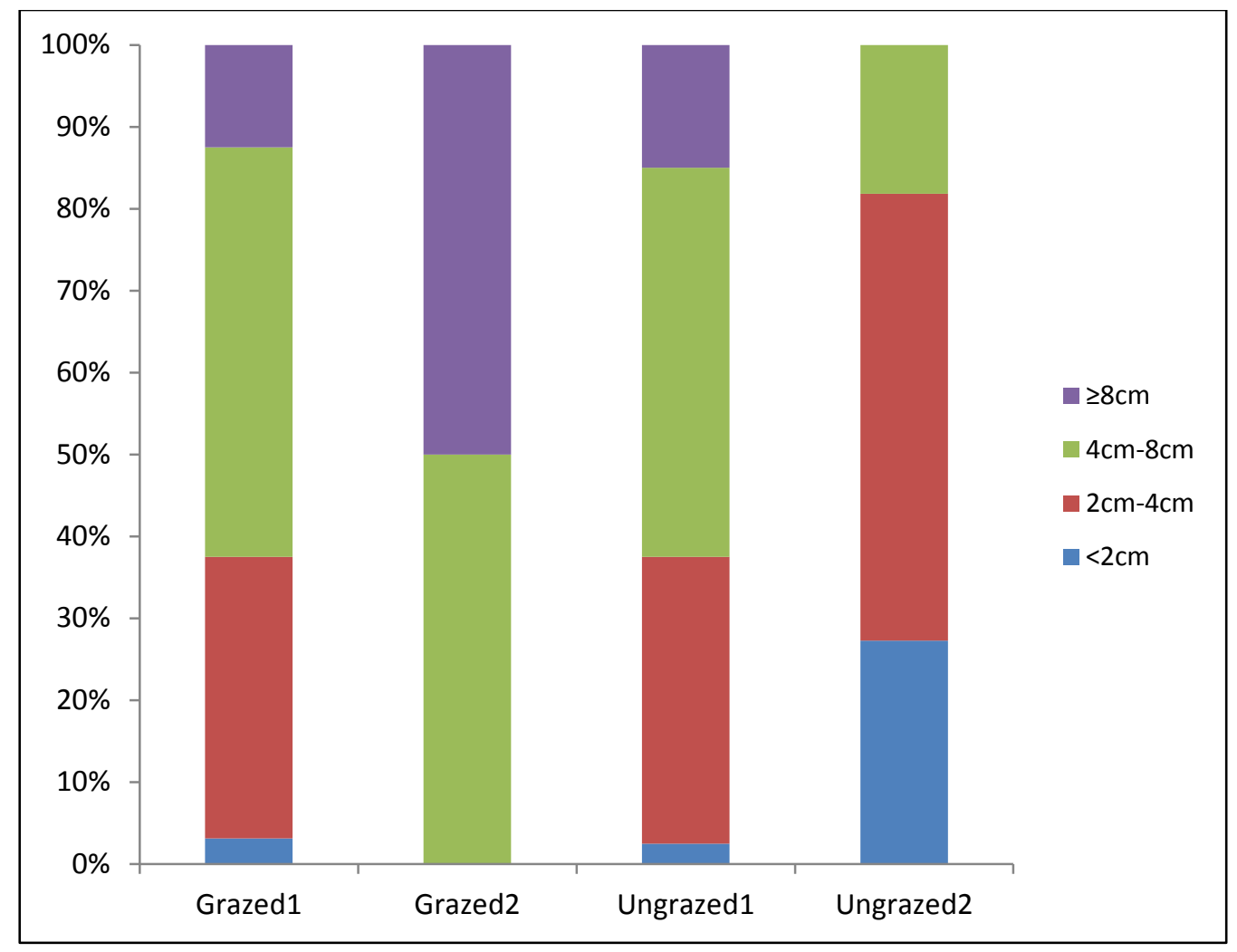

Figure 18. Distribution of small mammal hole entrance diameter for two grazed and two ungrazed sites. Entrance diameters were classified as either less than $2 \mathrm{~cm}, 2 \mathrm{~cm}$ $4 \mathrm{~cm}, 4 \mathrm{~cm}-8 \mathrm{~cm}$ or greater than $8 \mathrm{~cm}$. 


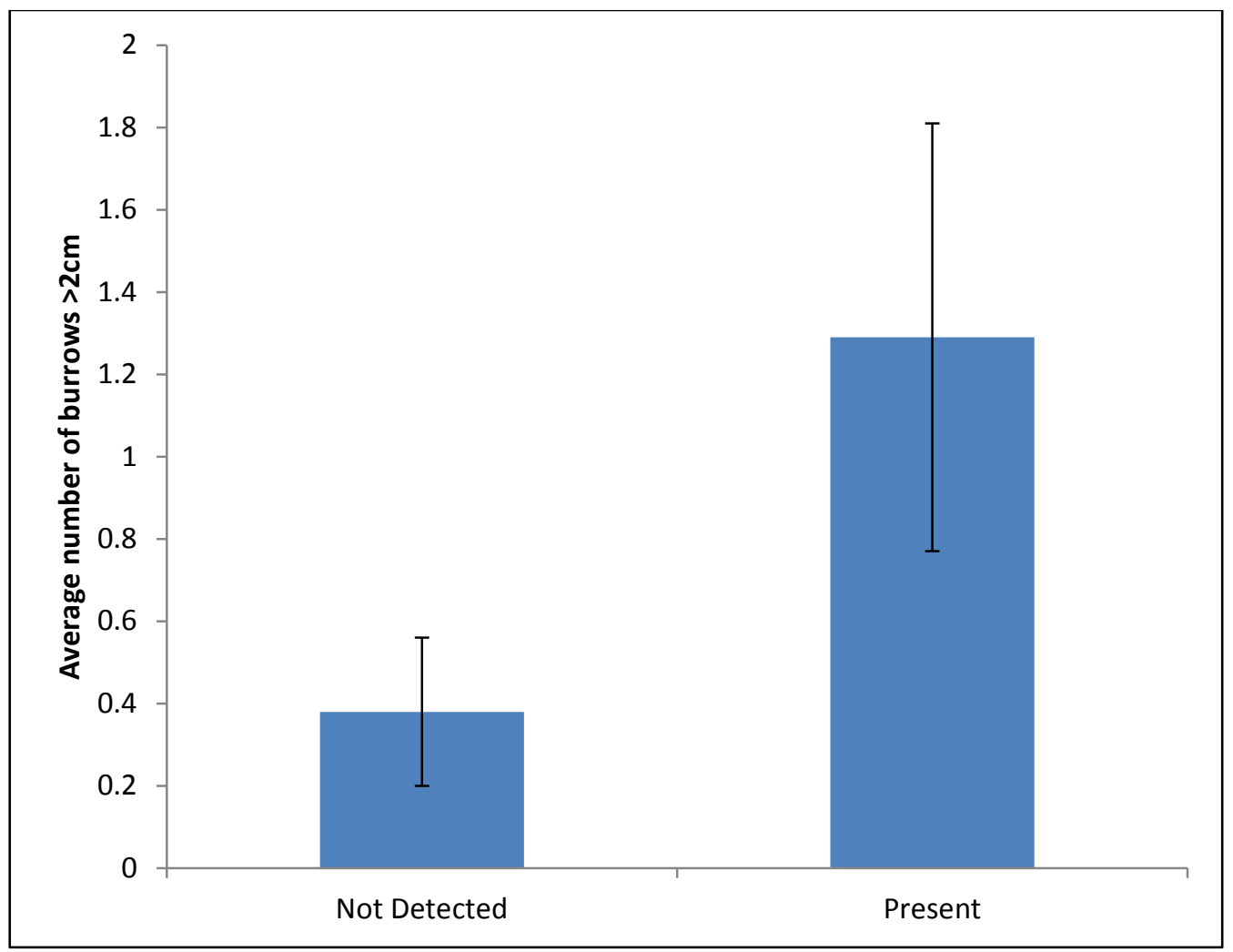

Figure 19. Average \pm SE number of burrows at arrays where Uta stansburiana was observed and at arrays where Uta stansburiana was not detected 


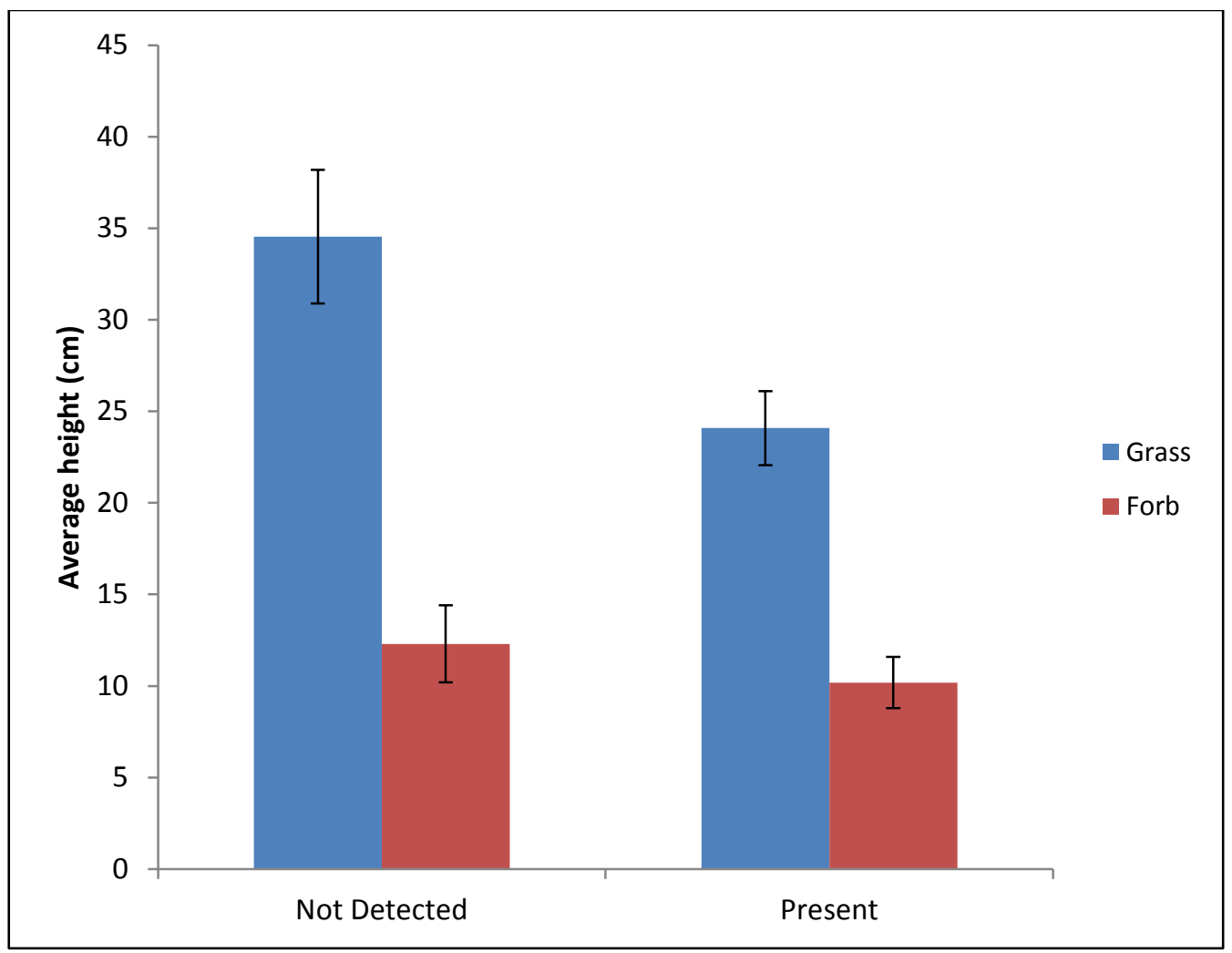

Figure 20. Average \pm SE canopy height of grasses and forbs at arrays where Uta stansburiana was observed and at arrays where Uta stansburiana was not detected. Average height at an array was calculated using the average height at each quadrat. 


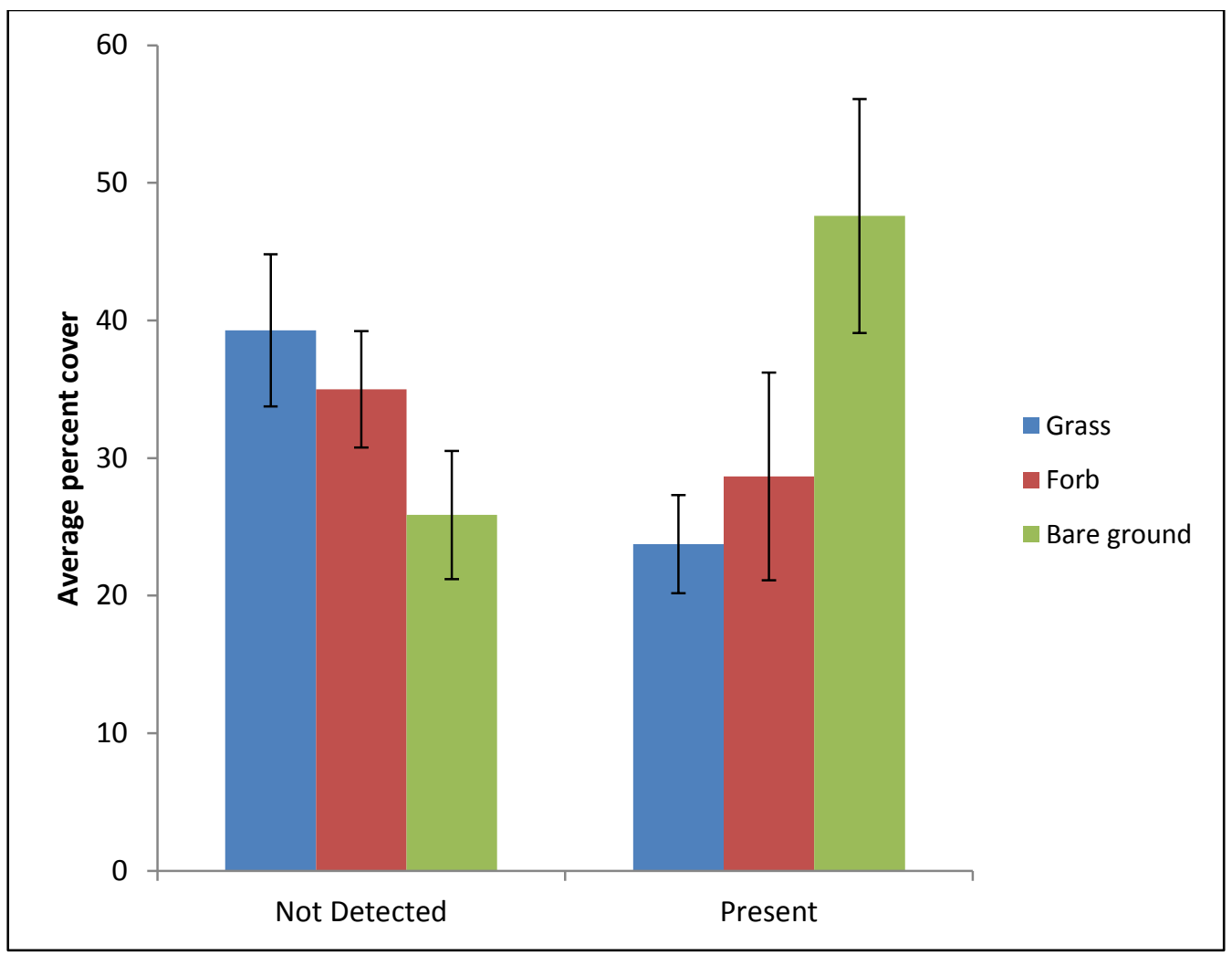

Figure 21. Average \pm SE percent cover of grasses, forbs, and bare ground at arrays where Uta stansburiana was observed and at arrays where Uta stansburiana was not detected. Average percent cover was calculated using the average cover across quadrats at an array. 